\title{
Rheological and physicochemical evaluation of dispersion systems based on enzymatically modified animal fat
}

\author{
Małgorzata Kowalska $^{1} \cdot$ Magdalena Woźniak ${ }^{1,2} \cdot$ Anna Krztoń-Maziopa $^{3}$ \\ Received: 18 January 2019 / Revised: 6 July 2019 / Accepted: 28 July 2019 / Published online: 30 August 2019 \\ (C) The Author(s) 2019
}

\begin{abstract}
The aim of the study was the rheological and physicochemical analysis of dispersion systems containing waste hard fat (mutton tallow) enzymatically modified with hemp oil. The addition of water to the reaction during fat modification allowed for direct preparation of product together with emulsifiers which remain in the final product as a fats' component. The idea of using waste, generally believed as useless mutton tallow for modification and simultaneously enriching it by unsaturated fatty acids derived from vegetable oil, is clearly a novel aspect of the presented work. The performed analysis showed that the highest physicochemical stability was observed for emulsions containing the highest amount of monoacylglycerols and diacylglycerols formed during interesterification. These emulsions showed only slight variations of average particle size during the entire storage period. Rheological assessment also confirmed that emulsions based on interesterified fats showed the best resistance against emulsion destabilization. Moreover, it has been found that materials with higher amounts of polar fraction exhibited the fastest recovery of microstructure after high shear loads.
\end{abstract}

Keywords No-waste technology $\cdot$ Lipase $\cdot$ Waste fat $\cdot$ Rheological measurements $\cdot$ Turbiscan analysis

\section{Introduction}

Most natural fats and oils, due to their quite specific content of fatty acids and triacylglycerols, have limited use in their unchanged form (Ribeiro et al. 2009). In order to extend, or improve the chemical composition of fat, specific modifications by chemical transformations and physical processes are used. Interesterification is currently the main alternative to the production of soft fats. The process itself does not change the total amount of fatty acids, but affects their mutual relations in the final product. Such modification significantly influences the physical, chemical, and functional properties of

Małgorzata Kowalska

mkowalska7@vp.pl

$1 \quad$ Faculty of Material Science, Technology and Design, Kazimierz Pulaski University of Technology and Humanities, 27 Chrobrego St, 26-600 Radom, Poland

2 Faculty of Economic and Legal Sciences, Kazimierz Pulaski University of Technology and Humanities, 33 Chrobrego St, 26-600 Radom, Poland

3 Faculty of Chemistry, Warsaw University of Technology, Noakowskiego 3, 00-664 Warsaw, Poland transformed fats. This applies in particular to the food industry, where interesterification is used to change the melting and fat crystallization characteristics to achieve a certain functionality, such as spreadability, specific melting point or profile of solid contents at a given temperature. This method is commonly accepted by the food industry as an alternative to partial hydrogenation of oils. The products obtained by this method do not contain trans-isomers as opposed to the hydrogenation process. In addition, such a modification is often used to enrich hard fats with unsaturated fatty acids derived from vegetable oils (Kowalska et al. 2015). One of these methods is the enzymatic interesterification that is used for the synthesis of triacylglycerols (TAG) with a specific positional composition using enzymes (obtained from microorganisms such as bacteria, yeasts, and fungi such as Candida rugosa or Mucor miehei) with regiospecific targeting of the fatty acid to specific position in the triacylglycerol molecule (Berry 2009).

Lipases, due to the high selectivity and purity of the products obtained in their use, are considered to be highly effective catalysts for inducing controlled hydrolysis and interesterification of vegetable fats and oils. The use of such lipases avoids unfavorable processing conditions, for example, high temperatures required by chemical modifications that can lead to thermal degradation of products and concomitant formation 
of unwanted side products. The modification of fats with the use of lipases also allows the formation of new fat blends with the desired functional and nutritional properties, which makes this method particularly useful in the large-scale production of modified triglycerides, and for the improvement of low-level fats (Paiva et al. 2000; Sharma et al. 2001).

One of the important factors is the water content in commercial enzyme preparations used as reaction biocatalysts (Tarnowska et al. 2013). It is important in both its presence and the amount that activates the catalyst and leads to the intended changes occurring during the interesterification process (Lortie 1997). The process, which is carried out in parallel with interesterification, is the hydrolysis of fat. The addition of larger amounts of water to the enzyme preparation shifts the equilibrium between the interesterification process and the hydrolysis of the fat resulting in the emergence of a larger amount of the polar fraction composed of monoacylglycerols (MAG) and diacylglycerols (DAG) in the newly formed fat mixture.

The goal of presented work was to create a new stable emulsion system, based on modified fats, which are not available from natural sources. Physicochemical evaluation, as well as detailed analysis of the rheological properties of the emulsions, allowed for the selection of systems containing sufficient amount of stabilizing substances formed during modification of hard fat with hemp oil. It has been shown that during the interesterification process, it is possible to form animal fat enriched with vegetable oil, which can be utilized in the preparation of stable emulsion systems of desired rheological properties without adding synthetic emulsifiers. Moreover, in our work, we have proposed a novel method for management of waste animal fats (mutton tallow). In general, the interest in animal fats is negligible. Mostly partial hydrogenation of vegetable oils is carried out to obtain incompletely hardened fats. However, from the nutritional point of view, this process is persistently controversial due to formation of unfavorable trans isomers. In this study, an enzymatic interesterification of fats is proposed as an alternative to the chemical interesterification process. In this reaction, a specific hydrolytic enzyme is used as a catalyst, which is an environmentally friendly substrate. The enzymatic modification is a waste-free reaction and the obtained products are safe.

\section{Materials and methods}

\section{Materials}

Hemp Oil (Oleofarm) with the following fatty acid profile was used: C16:0 7.8\%, C18:0 2.7\%, C18:1 (9-cis) 10.7\%, C18:1 (9-trans) $0.8 \%, \mathrm{C} 18: 2$ (all-cis) n-6 54.8\%, C18:3 (all-cis) n-6 $2.7 \%, \mathrm{C} 18: 2$ (all-cis) n-3 18.7\%, C20:0 1.2\%, C20:1 0.5\%, other $0.2 \%$. Mutton tallow was characterized by the following fatty acid profile: $\mathrm{C} 14: 06.4 \%, \mathrm{C} 16: 027.8 \%, \mathrm{C} 16: 11.2 \%$, C17:0 2.0\%, C18:0 28.2\%, C18:1 (9-cis) 23.3\%, C18:1 (9trans) $2.7 \%, \mathrm{C} 18: 2$ (all-cis) n-6 1.9\%, C18:2 (all-cis) n-3 $0.6 \%$, other $5.8 \%$.

Lecithin was obtained from Lasenor. Synthesized diacylglycerols (DAG) were obtained from monoacylglycerols (MAG) using acid-catalyzed solvent-assisted conditions. Detailed description of a procedure and characteristics of MAG can be found in Pazdur et al. (2015)). Lipase, from Rhizomucor Miehei immobilized on immobead 150, $\geq$ $300 \mathrm{U} / \mathrm{g}$ was obtained from Sigma-Aldrich.

\section{Methods}

\section{Fat modification}

Enzymatic interesterification was performed for mutton tallow and hemp oil fat blends, in a ratio of $1: 1(w / w)$, using immobilized biocatalyst-lipase, from Rhizomucor Miehei ( $5 \% \mathrm{w} / \mathrm{w}$ in relation to the fat blend mass). The reaction was carried out in a thermostated water bath at a temperature of $60{ }^{\circ} \mathrm{C}$ during $6 \mathrm{~h}$ with continuous shaking. Together with the catalyst, a certain amount of water was added to the fat blends (to obtain the following total amount of water in the reaction blend: $0.50,0.55,0.60,0.65,0.70,0.75,1.00$, and $1.25 \%, w /$ $w)$. Water was added to increase the content of the polar fraction (including MAG and DAG).

\section{Emulsion preparation}

Oil phases of eight prepared emulsions (coded later in the text as EM1-EM8) contained only interesterified fat blends (without additional emulsifier). The content of emulsifiers in each emulsion was varied and depended on the amount of water added to the reaction fat blend during interesterification (Table 1). Oil phases of emulsions EM9 and EM10 were prepared by mixing appropriate amount of non-esterified fat blend and emulsifier (Table 1). Aqueous phase of emulsions (EM1-EM10) was prepared by dispersing a thickener (carboxymethylcellulose-CMC) in distilled water prior to the emulsion preparation. Next, both oil and aqueous phases were heated to the temperature of $50-55{ }^{\circ} \mathrm{C}$, mixed and finally homogenized for $4 \mathrm{~min}$, using T18 digital ULTRATURRAX homogenizer equipped with S18G-19G dispersing head (IKA, China).

\section{Turbiscan test}

Stability of the emulsion was evaluated using Turbiscan Lab (Formulation, France) by measurement of the light intensity, at a wavelength of $880 \mathrm{~nm}$, backscattered by the sample. The measurement methodology is consistent with following publications (Huck-Iriart et al. 2011; 
Table 1 Composition of emulsions

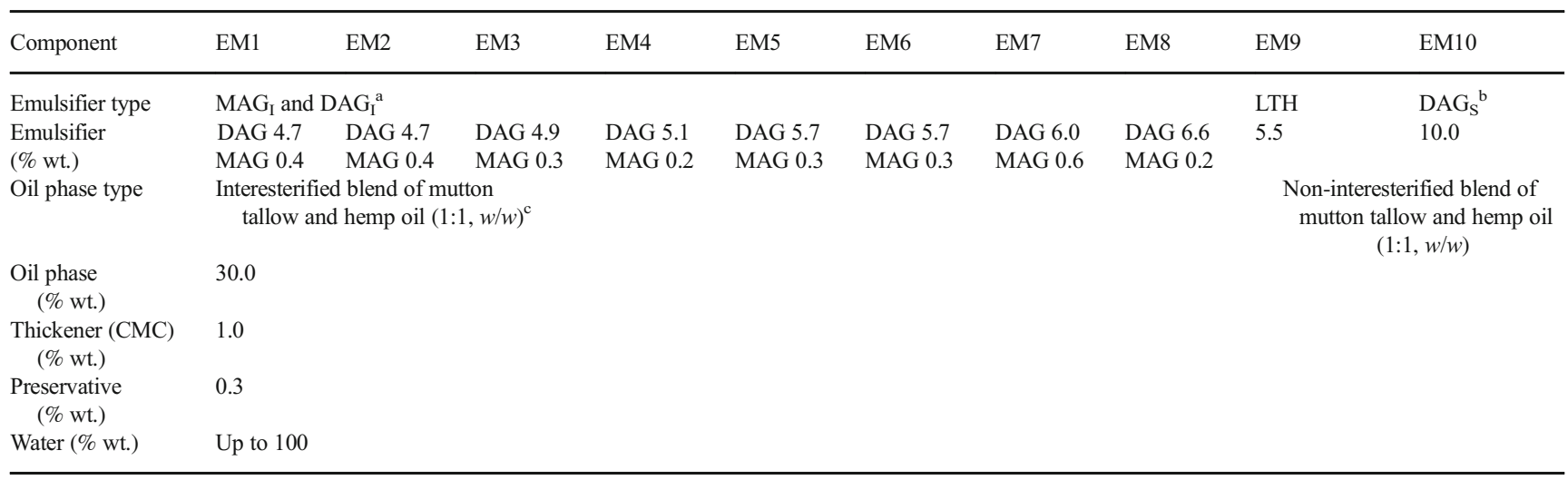

${ }^{\mathrm{a}} \mathrm{MAG}_{\mathrm{I}}$ and $\mathrm{DAG}_{\mathrm{I}}$ represent MAG and DAG formed during interesterification

${ }^{\mathrm{b}} \mathrm{DAG}_{\mathrm{S}}$ represents synthetic DAG

c Please refer to "Fat modification" section for details of interesterification conditions

LTH lecithin

Mengual et al. 1999; Cerimedo et al. 2010). The results were presented as the difference of backscattered light $(\Delta \mathrm{BS})$ with respect to the first measurement performed for a freshly prepared emulsions. The examination was performed every few days, during a total measuring period of 32 days. $\triangle B S$ profiles were plotted using a TurbiSoft 2.0. software.

\section{Increase of emulsions' droplet size}

The determination of the increase of emulsions' droplet size was carried out using Turbiscan Lab (Formulation, France) based on the dependence of backscattered light intensity change on the average droplet size (D) and volume fraction $(\varnothing)$, i.e., $B S=f(D, \varnothing)$, according to the method described in details by Cerimedo et al. (2010). Calculations were performed using TurbiSoft 2.0. software.

\section{Color of the emulsions}

Color was analyzed by a Konica Minolta chromameter CR-400 (Konica Minolta Sensing Inc., Milton Keynes, UK). The values of $\mathrm{L}^{*}, \mathrm{a}^{*}$, and $\mathrm{b}^{*}$ were determined in triplicate for each emulsion. CIEL*a*b* system was used to assess emulsion color. $L^{*}$ value represents lightness of the sample ranging from $0=$ black to $100=$ white, $a^{*}$ and $b^{*}$ expressed two perpendicular color axes, with the values ranging from -60 to +60 . $a^{*}$ expresses greenness when negative and redness when positive, in the case of $b^{*}$, blueness when negative, yellowness when positive (Gouveia et al. 2006; Estanqueiro et al. 2014). The measurements were taken on stored emulsions (30 days, $5{ }^{\circ} \mathrm{C}$ ).

\section{Optical microscopy}

Morphology of emulsion droplets was observed and photographed using a Jangar LCD-3.5 microscope at $\times 500$ magnification. Microphotographs were taken after 1 month of storage. In order to determine particle size distribution, the diameter of dispersed phase droplets was measured manually from the obtained microphotographs. Five fields of view for each emulsion were used.

\section{Rheological analysis}

Rheological analysis of the prepared emulsions was performed with Anton Paar Physica MCR 301 rheometer equipped with air bearing and parallel plate measuring geometry (plate diameter: $50 \mathrm{~mm}$, measuring gap $1 \mathrm{~mm}$ ). All the measurements were performed at constant temperature $20 \pm 0.02{ }^{\circ} \mathrm{C}$. Temperature was controlled with a built-in Peltier device. Dynamic rotational tests in a controlled shear stress mode were performed to obtain the flow characteristics and estimate the yield points of the prepared materials. The consistency and the viscoelasticity of all the emulsions were investigated using small strain amplitude oscillatory tests at constant frequency. In addition, frequency sweeps with imposed small strain amplitude, chosen from linear viscoelastic range, were recorded within few decades (0.01-100 rad/s) and then employed for an assessment of the possible destabilization effects (creaming, coalescence, etc.) that may appear in the emulsion after prolonged storage. Thermal destabilization of the studied materials was investigated in a rotational mode at temperatures in the range $0-50{ }^{\circ} \mathrm{C}$. Temperature range was chosen based on the typical thermal conditions met during preparation, storage, transportation and application of cosmetic emulsions. 


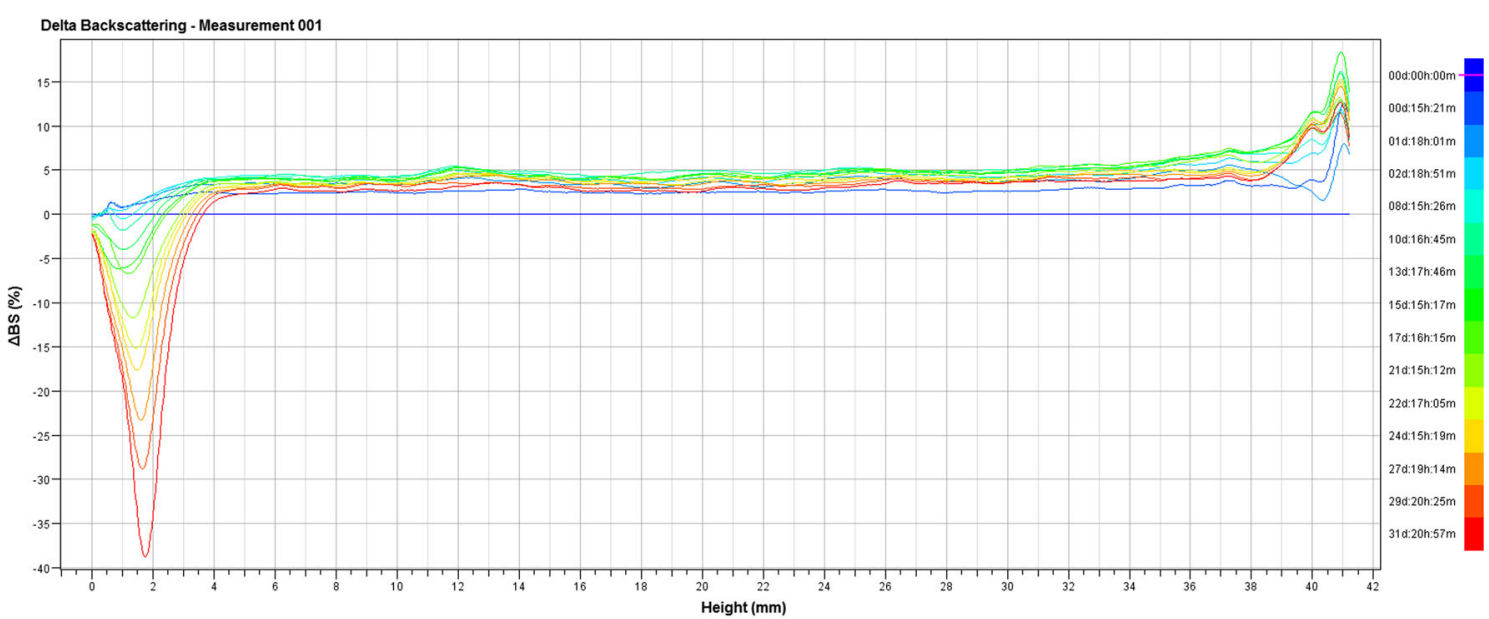

Fig. $1 \Delta$ BS profile for EM2 (presented as typical for EM1-EM6) as a function of time and sample height

\section{Results and discussion}

The enzymatic interesterification process allowed to modify waste food industry product, which is mutton tallow, by creating new fat blends enriched with unsaturated fatty acids derived from hemp oil. The obtained interesterified blends were characterized by more delicate and homogeneous structure compared to non-interesterified blend.

The legitimacy of introducing additional unsaturated fatty acids was dictated by their beneficial external and internal impact on the human body (Boelsma et al. 2001). Polyunsaturated fatty acids (PUFA) are the starting materials for the biosynthesis of eicosanoids: prostaglandins, prostacyclins, thromboxanes, and leukotrienes (WiktorowskaOwczarek et al. 2015). They are involved in cholesterol transport and oxidation, as well as constitute a component of cell membranes' lipids. A commonly known feature of PUFA is their positive effect on the cardiovascular system. Moreover, PUFA decrease cholesterol level, reduce synthesis of triacylglycerols, inhibit platelets aggregation, and slightly lower blood pressure (Rustan and Drevon 2005).
As a result of the enzymatic modification, a larger amount of monoacylglycerols and diacylglycerols was obtained. To receive the smallest amount of MAG and DAG, which could stabilize the emulsion, a different amount of water was added to the reaction systems to force partial hydrolysis of the triacylglycerols. The highest amount of DAG derived from mutton tallow and hemp oil triacylglycerols was observed for fat blends which constituted a basis for emulsions EM7 and EM8 (Table 1).

\section{Stability of emulsions}

In the present work, Turbiscan test was used to assess the stability of emulsion systems (EM1-EM10). The aim of the analysis was to determine the profiles of backscattered light (BS) intensity for the each sample. According to Huck-Iriart et al. (2011) this determination is a reliable tool for evaluation of the changes, which are taking place in the dispersion system. Furthermore, the same authors stated that the profiles of BS light intensity can be considered as a specific macroscopic fingerprint of an emulsion. Therefore, it is possible to identify

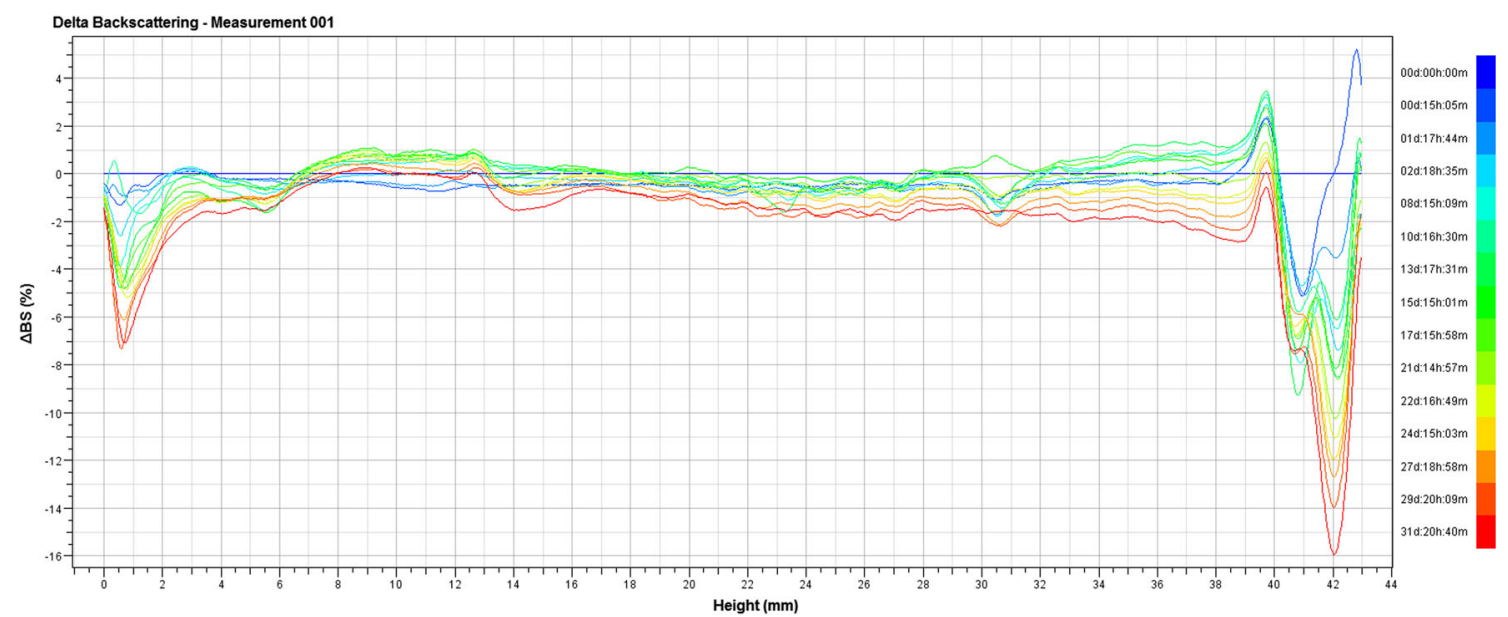

Fig. $2 \Delta$ BS profile for EM8 (presented as typical for EM7-EM8) as a function of time and sample height 


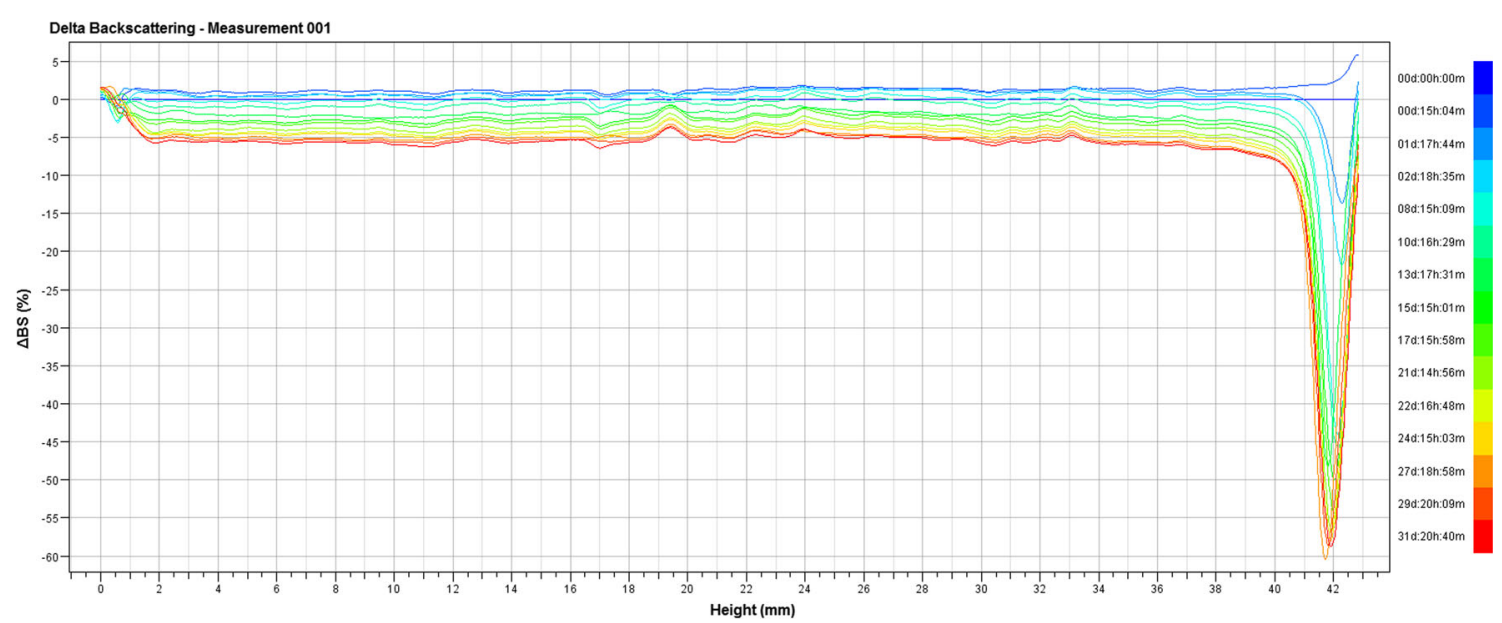

Fig. $3 \Delta$ BS profile for EM9 as a function of time and sample height

and observe changes of instabilities in the sample over time (Mengual et al. 1999).

Figure 1 shows backscattering profiles in the reference mode $(\triangle \mathrm{BS}(\%))$ for emulsions EM1-EM6 with respect to emulsion EM2 taken as a reference. Analyzing the obtained profiles, it was found that in samples EM1-EM6, several mechanisms of destabilization occurred at the same time. Local variations of $\triangle \mathrm{BS}$ in the lower and upper part of the measuring cell as well as global variations in the entire sample were observed. The appearance of a negative peak in the lower part confirms the emulsion clarification at the bottom of the sample, while the positive peak in the upper part is attributed to the formation of more dense phase due to creaming process (Robins 2000). Creaming is related to the density difference between the bulk and the dispersed phases and occurs in $\mathrm{O} / \mathrm{W}$ emulsions (Ghanbari et al. 2017). In EM1-EM6 samples, additional features in the middle part of the graph were also observed, indicating an increase of the particles' diameter of the dispersed phase (flocculation or coalescence). According to Cerimedo et al. (2010), changes in the intensity of BS light result in changes in the size of the emulsion's average particle size (D) and on the particle volume fraction (ø), i.e., $B S=f(D$, ø). Thus, observed changes in particle size can be attributed to the particles' aggregation and coalescence, leading to an increase in the average particle size of an emulsion. As a consequence of these phenomena, creaming was observed, i.e., gravitational separation.

The beginning of phase separation of these systems (EM1EM6) was dependent on time and total amount of emulsifiers in the system. The earliest phase separation was observed for the EM1 sample on day 2 (data in Appendix). The EM1 emulsion contained the smallest amount of emulsifiers formed during interesterification. At the latest, phase separation occurred in sample EM6 (data in Appendix). Analyzing the above results, it was found that the amount of emulsifiers produced during enzymatic interesterification in a fatty base of emulsions EM1-EM6 was not sufficient to stabilize the dispersion system.

In the case of EM7 and EM8 samples, containing the highest amount of emulsifiers produced in the

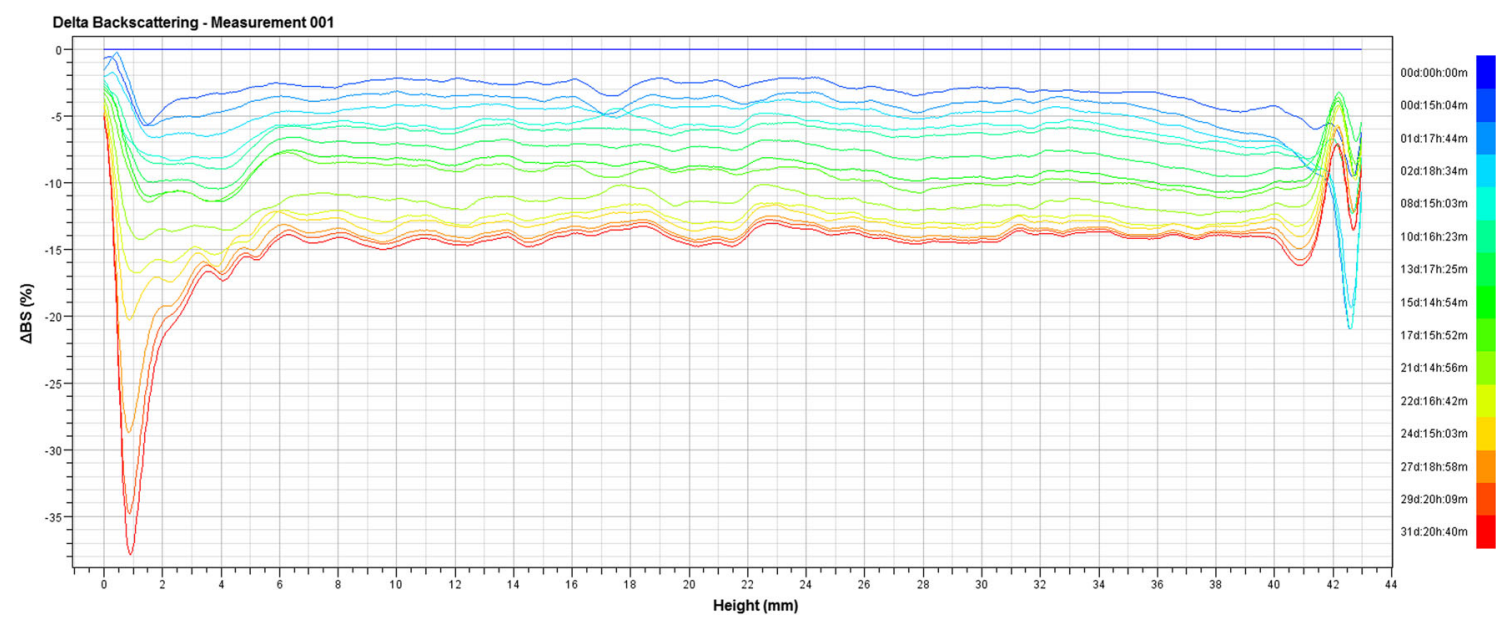

Fig. $4 \Delta$ BS profile for EM10 as a function of time and sample height 


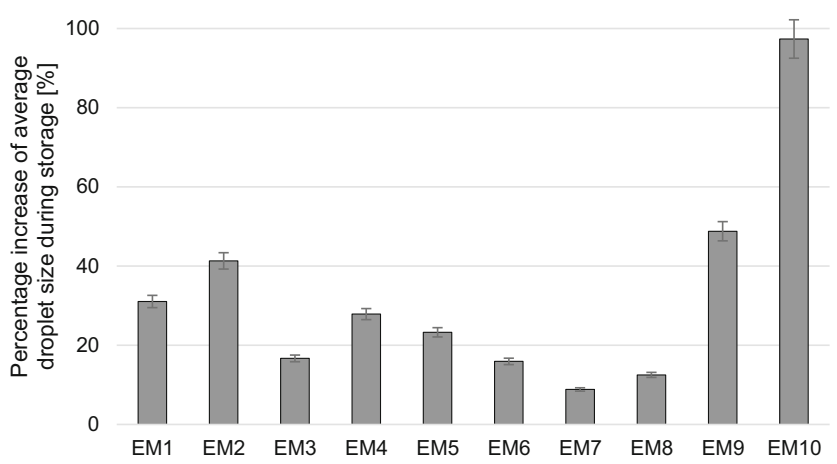

Fig. 5 Percentage increase of average droplet size of emulsions EM1EM10 during storage

interesterification process, the smallest changes of the $\Delta \mathrm{BS}$ values were observed (Fig. 2). The high stability of these systems was confirmed by nearly unchanged profiles of BS light intensity (overlapped curves in Fig. 2) during the entire storage period. The $\Delta \mathrm{BS}$ values in the middle part of the sample varied within $2 \%$, which also indicated that there was no significant change in the particle size of these emulsions during storage. For these systems, no changes characteristic for creaming process, nor phase separation were observed.

Figures 3 and 4 present BS profiles in the reference mode $(\triangle \mathrm{BS}(\%))$ for emulsions EM9 and EM10, respectively. For these samples, significant changes were observed in the BS light intensity profiles at the entire sample height in subsequent scans during emulsion storage. Considerable distances were observed between the curves recorded for the subsequent measurements, which indicated an increase in the average droplet size of the system with time of storage. Definitely, the largest changes in the droplet size were observed for the EM10 emulsion, which contained synthetic diacylglycerols. According to earlier reports concerning measurements of droplet size distribution in emulsion systems with similar methods (Chauvierre et al. 2004; Palazolo et al. 2005), it can be assumed that our emulsions were also characterized by a

Table 2 CIELAB $L^{*}, a^{*}, b^{*}$ values of emulsions EM1-EM10 stored 30 days at $5{ }^{\circ} \mathrm{C}$ (as a mean value of three determinations $\pm \mathrm{SD}$ )

\begin{tabular}{llll}
\hline & L* & a* & $\mathrm{b}^{*}$ \\
\hline EM1 & $46.01 \pm 0.02$ & $-2.38 \pm 0.02$ & $8.74 \pm 0.01$ \\
EM2 & $47.06 \pm 0.44$ & $-2.85 \pm 0.03$ & $10.74 \pm 0.06$ \\
EM3 & $48.87 \pm 0.03$ & $-2.55 \pm 0.04$ & $9.19 \pm 0.04$ \\
EM4 & $49.12 \pm 0.02$ & $-2.72 \pm 0.01$ & $9.82 \pm 0.01$ \\
EM5 & $36.55 \pm 0.13$ & $-2.95 \pm 0.03$ & $14.05 \pm 0.04$ \\
EM6 & $41.35 \pm 0.04$ & $-2.21 \pm 0.08$ & $8.18 \pm 0.00$ \\
EM7 & $45.18 \pm 0.14$ & $-2.10 \pm 0.03$ & $8.00 \pm 0.06$ \\
EM8 & $56.07 \pm 0.03$ & $-2.85 \pm 0.04$ & $10.66 \pm 0.02$ \\
EM9 & $59.66 \pm 0.15$ & $-1.68 \pm 0.09$ & $12.72 \pm 0.24$ \\
EM10 & $6.71 \pm 0.28$ & $-2.01 \pm 0.12$ & $7.93 \pm 0.29$ \\
\hline
\end{tabular}

wide particle size distribution, because the variations of BS light intensity were observed at the entire height of the samples for individual measurements. The confirmation of this assumption could be the particle size analysis using laser diffraction method.

\section{Increase of emulsions' droplet size}

Figure 5 shows the percentage increase of average droplet size of emulsions EM1-EM10 during storage ( 32 days, $30^{\circ} \mathrm{C}$ ). In general, a smaller increase of average droplet size in emulsions containing emulsifiers formed during the interesterification process was observed. The smallest increase was detected for EM7 and EM8, 9\% and 13\%, respectively. The largest increase, almost double compared to the initial value, was noted for EM10, which contained synthetic DAG as emulsifiers. Also, a significant increase (49\%) occurred for EM9, in which the lecithin was used as an emulsifier.

\section{Color of emulsions}

Taking into account the colorimetric evaluation, carried out 1 month after the manufacturing of emulsion systems, as well as a visual assessment, it can be concluded that the investigated emulsions were characterized by green and yellow tones (Table 2, Fig. 6). The darkest color was shown by the EM10 sample containing synthetic diacylglycerols. The remaining emulsions were much brighter compared to the EM10 emulsion, and their brightness was determined in the range (41.3559.66). The $b *$ parameter has been characterized for nearly all emulsions as a shade of yellow. The highest values for this shade of color were determined for emulsions EM2, EM8, EM9. In turn, for the parameter a $*$ determining the share of green and red, negative values of this feature were noted, indicating a significant share of green in the general tone of this emulsion. Considering raw materials from which fatty mixtures were prepared, and then emulsions, it can be concluded that the green color came from hemp oil, which contains high amount of chlorophyll pigments (Teh and Birch 2013). Emulsion EM5 revealed low $\mathrm{L} *$ values and high $\mathrm{b} *$ values at the same time, which could be caused by destabilization processes. According to McClements (2007), coalescence may lead to color changes of an emulsion, due to difference in light scattering by larger droplets. Based on that, it can be concluded that emulsion color becomes deeper when coalescence occurs.

\section{Optical microscopy}

In the microscopic image of the prepared emulsions, the complexity of their structure is clearly visible. In most of them, there were differences in the size of droplets constituting a dispersed phase. The smallest droplets of a similar size were observed for the emulsion EM7 and EM8 (Fig. 7). A fairly 
Fig. 6 Photographs of the emulsions EM1-EM10: a after $24 \mathrm{~h}, \mathbf{b}$ after 30 days of storage at $30{ }^{\circ} \mathrm{C}$ a)

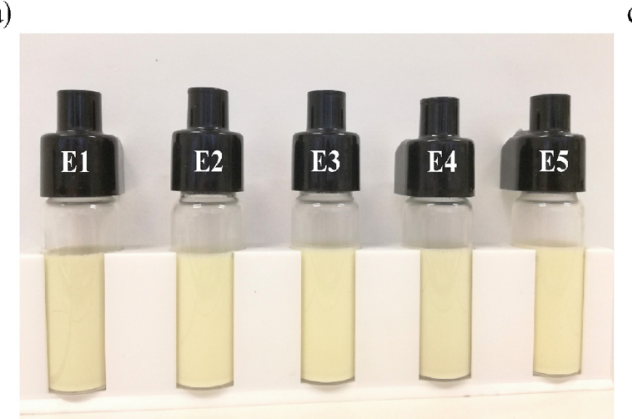

b)

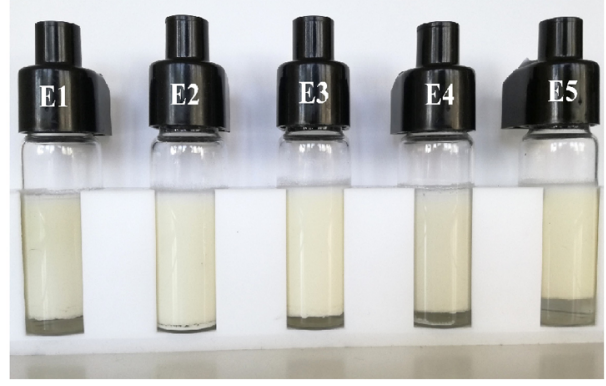

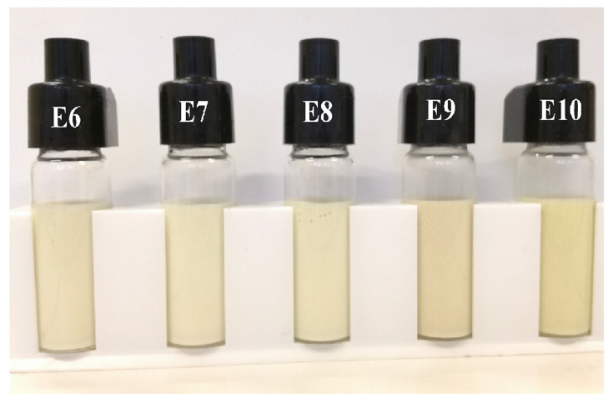

d)

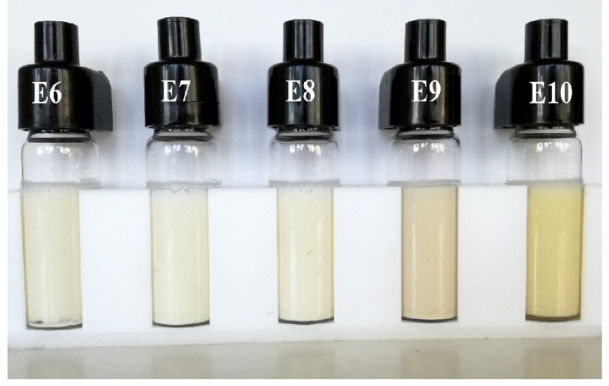

homogeneous size of droplets was also characteristic of emulsion EM9 (Fig. 7), although the presence of single larger droplets in it affected the reduced assessment and ultimately allowed to qualify these changes as a heterogeneity of the system. It also affected the total mean droplet size of the system, which consequently had an effect on changing the type of the physical system.

Emulsions containing emulsifiers formed during interesterification with an addition of water in a range of $0.70-1.25 \%$, i.e., EM5, EM6, EM7, and EM8, revealed the narrowest particle size distribution (Fig. 8). The diameter of the droplets after 30-day storage period was within a range of approximately $0.5-14.0 \mu \mathrm{m}$. Remaining emulsions with emulsifiers formed during interesterification, with water addition to the reaction system below $0.70 \%$ (EM1-EM4), were characterized by multimodal particle size distribution, which was correlated with the instabilities occurring in these samples, confirmed also by Turbiscan test. Moreover, for these emulsions, the range of droplet diameter was wider and the maximum droplet diameter was approximately $20.0-25.0 \mu \mathrm{m}$. Emulsion EM9, containing as an emulsifier lecithin, revealed a formation of additional new peaks (around 22 and $24 \mu \mathrm{m}$ ). Appearance of new fractions can suggest that the process of emulsion separation started. While EM10 with synthetic DAG was characterized as highly polydisperse system with multimodal particle size distribution.

\section{Rheological analysis}

Rheological properties of emulsion systems are crucial for determining their functional properties and thus affect their quality, as flow phenomena are involved both in the emulsion preparation and in their use (Barnes 1994; Gallegos et al. 2004; Brümmer 2006). Over few decades, various rheological models were constructed that can be used for fitting experimental data of diluted, semi-diluted, and dense emulsions. Both theoretical and empirical approaches were employed to correlate the emulsion viscosity, texture, and viscoelasticity with volume fraction of droplets present in emulsion systems (Schowalter et al. 1968; Palierne 1990). First report concerning the influence of droplet size distribution on emulsion rheology has been raised by Pal (1996)), who noted more pronounced shear thinning behavior of emulsions containing smaller droplets, and more importantly, a strong dependence of rheological properties on the droplet size distribution at the same volume fraction of dispersed phase. Further studies on this problem, carried by Salager et al., have shown that the lowest apparent viscosities were observed for emulsions with the highest polydispersity indexes (Salager et al. 2001). Intense studies on emulsion rheology allowed later for formulation of several constitutive models describing rheological behavior of monodisperse emulsions (Pal 2001, 2003). An important progress in rheological modeling of dense emulsion systems composed of polydisperse droplets can be found in the report of Baldyga et al. (2016), who considered the effect of droplet polydispersity on the rheological properties of emulsion viscosity by combining models proposed by Palierne (1990)) and Pal (2003)). Taking the above into account, to gain more information on rheological properties of our emulsions and compare them with other systems published in the literature, we have employed two fitting approaches. First one, involving fitting a general rheological model. The best fits were obtained with a Cross equation: $\eta=\eta_{\infty}+\frac{\eta_{0}-\eta_{\infty}}{1+(C \dot{\gamma})^{m}}$, where $\eta_{0}$ is the 
Fig. 7 Microscopic structure of emulsions stored 30 days at $5{ }^{\circ} \mathrm{C}$, from a EM1 to j EM10 a)

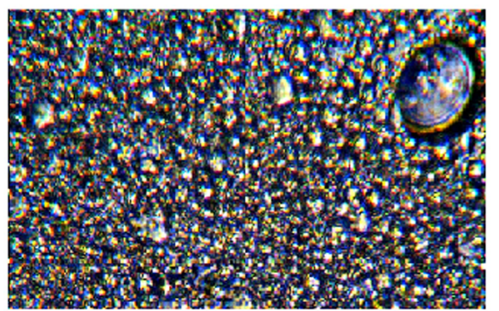

c)

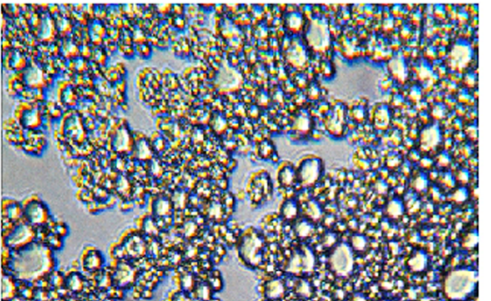

e)

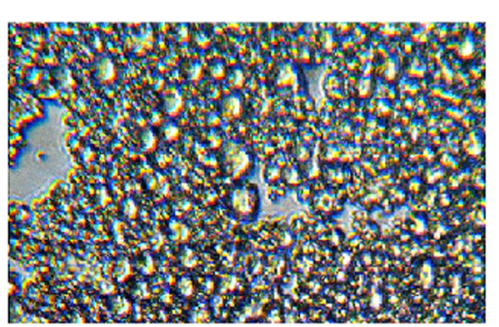

g)

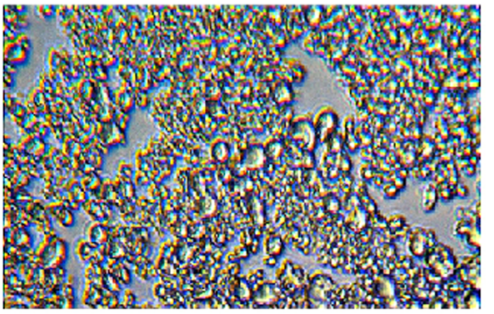

b)

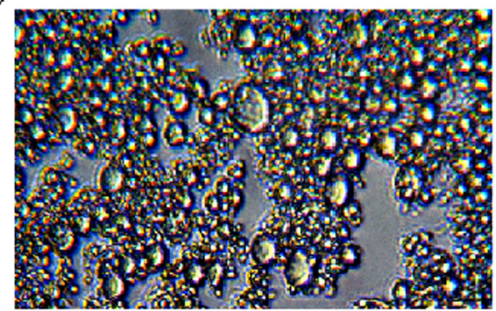

d)

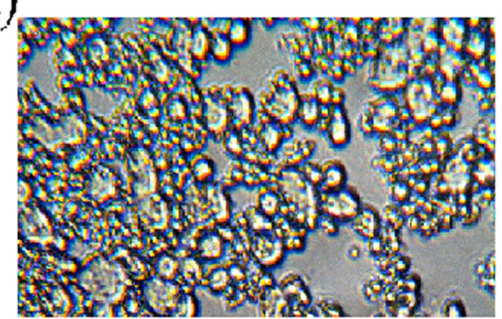

f)

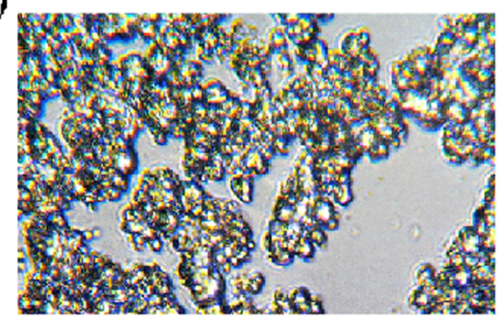

h)

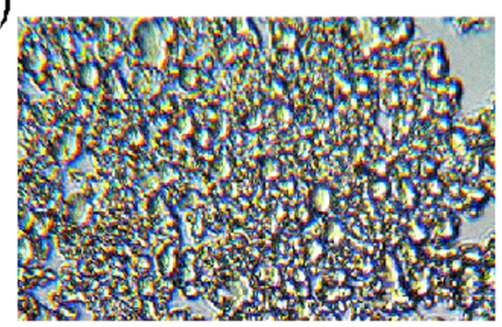

j)

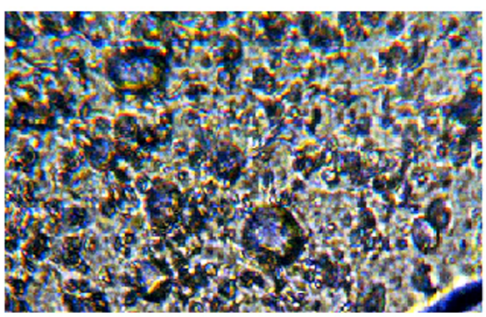

zero shear viscosity, corresponding to the viscosity of an emulsion at extremely small shear rates (lower Newtonian plateau) (Macosko and Larson 1994). The coefficient $\eta_{\infty}$ is the infinite shear viscosity indicating a viscous behavior at very high shear rates (upper Newtonian plateau). The exponent $m$, known as the Cross rate constant, reflects the steepness of the slope of a viscosity curve in the shear-thinning region; $m=0$ corresponds to the Newtonian flow, while $m$ close to 1 characterizes the shear thinning behavior of the investigated system. The parameter $C$ is understood as a consistency (or Cross time constant). The onset of a critical shear rate, at which shear thinning behavior begins, can be estimated from reciprocal of $C$. Parameters of fits with Cross model, together with goodness of fit $\left(R^{2}\right)$ coefficients, are collected in Table 3. Secondly, another fitting with a more detailed model that involves polydispersity of emulsion 
Fig. 8 Particle size distribution (by number) of the emulsions stored 30 days at $5{ }^{\circ} \mathrm{C}$ from a EM1 to j EM10
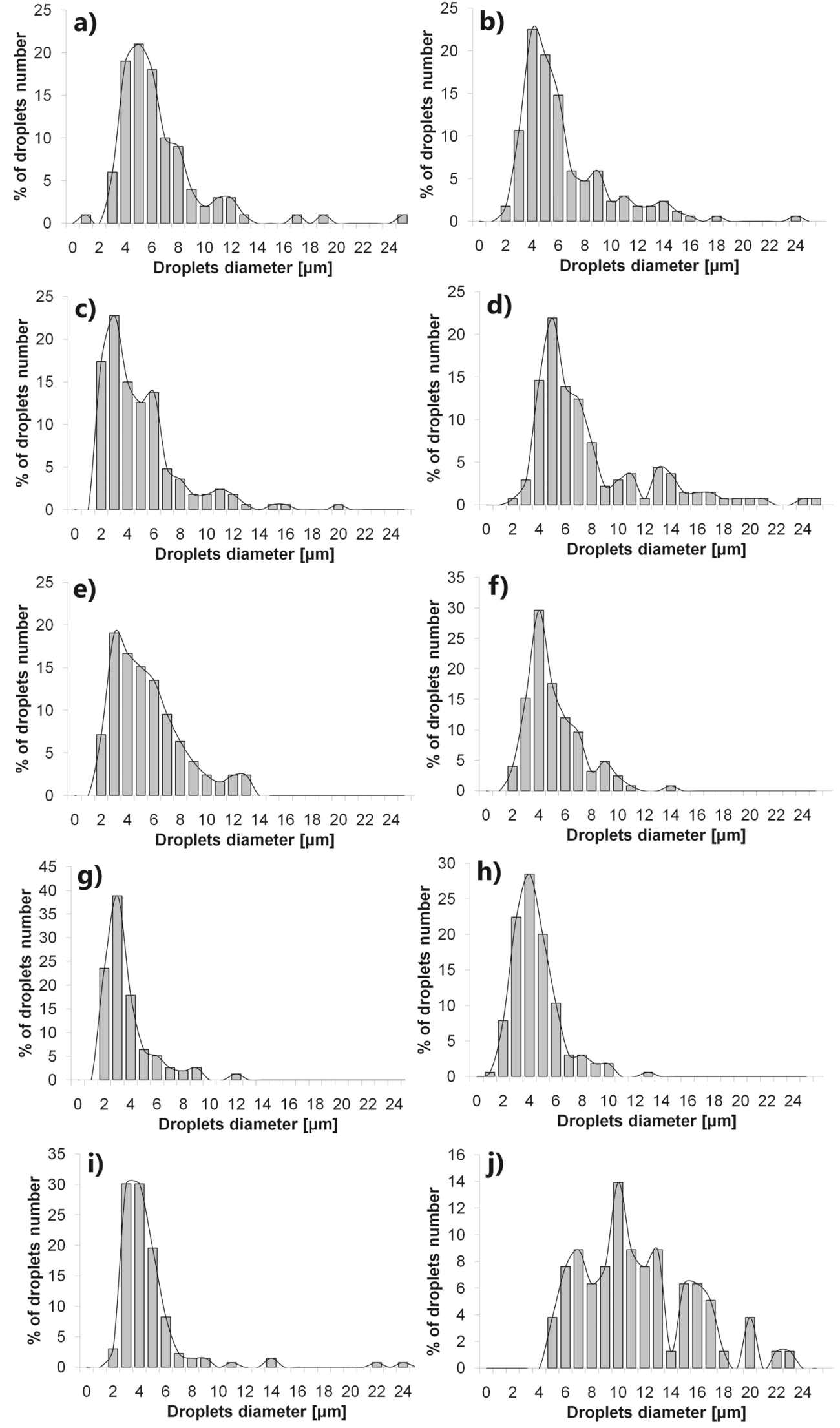
Table 3 Parameters of fitting of experimental data with a Cross model, goodness of fit coefficients $\left(R^{2}\right)$ for both models and average droplet size, and volume fraction of droplets for investigated emulsions

\begin{tabular}{lllllllll}
\hline Sample & $\begin{array}{l}\text { Zero shear viscosity, } \\
\eta_{0}[\mathrm{~Pa} \mathrm{~s}]\end{array}$ & $\begin{array}{l}\text { Infinite shear viscosity, } \\
\eta_{\infty}[\mathrm{Pa} \mathrm{s}]\end{array}$ & $M[-]$ & $\begin{array}{l}K[\mathrm{~s}] \\
m\end{array}$ & $\begin{array}{l}R^{2} \text { Cross } \\
\text { model }\end{array}$ & $\begin{array}{l}R^{2} \text { Baldyga } \\
\text { model }\end{array}$ & $\begin{array}{l}D i[\mu m] \text { average } \\
\text { droplet size } \\
\text { (stored emulsions) }\end{array}$ & $\begin{array}{l}\text { Volume fraction of } \\
\text { droplets } \\
\text { (fresh emulsions) }\end{array}$ \\
\hline EM1 & 1770 & 0.301 & 0.9175 & 120.5 & 0.9927 & 0.9816 & 7.2 & $0.67 \pm 0.025$ \\
EM2 & 2397 & 0.119 & 0.8579 & 139.8 & 0.9896 & 0.9963 & 6.5 & $0.77 \pm 0.015$ \\
EM3 & 3166 & 0.162 & 0.8743 & 145.8 & 0.9947 & 0.9910 & 4.9 & $0.69 \pm 0.03$ \\
EM4 & 2152 & $6.29 \cdot 10^{-2}$ & 0.8151 & 108.2 & 0.9943 & 0.9722 & 6.3 & $0.70 \pm 0.005$ \\
EM5 & 1841 & $7.04 \cdot 10^{-2}$ & 0.8240 & 99.8 & 0.9948 & 0.9907 & 3.8 & $0.78 \pm 0.011$ \\
EM6 & 2323 & $6.05 \cdot 10^{-2}$ & 0.7838 & 108.3 & 0.9963 & 0.9916 & 3.7 & $0.77 \pm 0.02$ \\
EM7 & 7307 & $5.83 \cdot 10^{-2}$ & 0.8049 & 231.9 & 0.9964 & 0.9976 & 3.4 & $0.76 \pm 0.009$ \\
EM8 & 8268 & $4.64 \cdot 10^{-2}$ & 0.7795 & 290.3 & 0.9965 & 0.9918 & 4.4 & $0.76 \pm 0.005$ \\
EM9 & 21,488 & 0.323 & 0.8981 & 307.6 & 0.9988 & 0.9959 & 4.9 & $0.73 \pm 0.010$ \\
EM10 & 21,954 & 3.853 & 0.9563 & 332.6 & 0.9944 & 0.9945 & 7.9 & $0.71 \pm 0.021$ \\
\hline
\end{tabular}

droplets in calculations of viscosity, proposed by Baldyga et al. in their report (Baldyga et al. 2016). Their model (denoted as JB- model further in the text) enables calculations of emulsion viscosity with regards to several parameters characterizing an emulsion system: volume fraction of droplets, their size distribution, viscosity of the dispersed phase and viscosity of dispersing medium, interfacial tension and the shear rate. Details of the model, together with all the equations, can be found in the original work (Baldyga et al. 2016). Here, main equations being a core of JB model are given. Emulsion viscosity can be calculated as

$$
\eta=\eta_{c}\left(1+5 \int_{0}^{\infty} f_{\mathrm{v}(\mathrm{Ri})} \mathrm{I}_{(\mathrm{Ri})} \mathrm{dRi}\right) \text {, where } \eta_{c} \text {-viscosity of the }
$$
dispersing medium, $f_{\mathrm{v}(\mathrm{Ri})} \mathrm{I}_{(\mathrm{Ri})} \mathrm{dRi}$-is a volume fraction of droplets, which size falls in the range $R i$ to $R i+d R i$, $I_{(R i)}=\frac{\left(4 / \mathrm{N}_{\mathrm{Ca}, \mathrm{i}}\right)(2+5 \mathrm{~K})+(\mathrm{K}-1)(16+19 \mathrm{~K})}{\left(40 / \mathrm{N}_{\mathrm{Ca}, \mathrm{i}}\right)(1+\mathrm{K})+(2 \mathrm{~K}+3)(16+19 \mathrm{~K})}$; capillary number $N_{C a}$, $i$ is calculated according to the following expression: $N_{C a, i}=R_{i} \eta_{c} \dot{\gamma} / \sigma$, where $\sigma$ is the interfacial tension, and $\mathrm{K}$ coefficient determines the value of the viscosity ratio of the dispersed phase to the viscosity of the dispersing phase. It has to be noted, however, that description of JB model involves only Newtonian media or as continuous phases and disregards non-Newtonian liquids, which in fact are present in many emulsion systems. In our case, the dispersing phase is a shear thinning fluid containing thickening agent (dissolved carboxymethylcellulose); therefore, its shear dependent viscosity was also taken into account in fitting procedure. For fitting purposes, we have modified slightly the original description of JB model by using shear dependent viscosity measured for the continuous phase in equation. Volume fractions of the dispersed phases estimated on the basis of electrical conductivity measurements according to the method described by McClements (2005)). The obtained values for the investigated systems are listed in Table 3. Volume fractions were used for viscosity calculations based on JB model. Results of fits with both models are shown in Fig. 9. The applied fitting procedures resulted in both cases similar goodness of fit coefficients; however, the JB model seems to work better in the low shear rates range. For shear rates above $10 \mathrm{~s}^{-1}$ in emulsions EM1-EM8, the JB model does not hold well in contrast to the Cross equation, which fits well the higher shear rate range. Fitting procedure performed by assumption of constant viscosity of the continuous phase gave much worse results, especially at higher shear rates (results of fitting not shown in the paper). Weaker correlation of the JB model with experimental data at higher shear rates can be attributed to enhanced hydrodynamic interactions between droplets deformed during flow and orientation of thickener macromolecules in the shear direction.

All the emulsions prepared with interesterified fat blends are characterized by relatively high values of $\eta_{0}$ viscosities followed by pronounced shear thinning behavior with increasing shear rate. It is noticeable that emulsions EM7 and EM8, prepared from fat blends with the highest polar fraction of acylglycerols, exhibit also higher zero shear viscosities, which clearly shows that this modification offers a convenient way for adjustment of the consistency of the prepared emulsions. Both lecithin-based material and physical mixture of fats exhibited few times larger $\eta_{0}$ viscosities in comparison to emulsions containing interesterified fat blends with lower content of polar fraction.

Utilization of emulsions in everyday use is closely related to their viscoelastic behavior that characterizes consistency of an emulsion at quasi-stationary state. To reveal the viscoelasticity of our emulsions and correlate their rheological behavior with the content of polar fractions in the interesterified fats used as the oil phase, we have additionally performed oscillatory tests. Figure 10 shows dependences of $\mathrm{G}^{\prime}$ and $\mathrm{G}^{\prime \prime}$ on imposed stress amplitude in the range $0.01-100 \mathrm{~Pa}$, obtained at constant angular frequency $1 \mathrm{rad} / \mathrm{s}$ for all the investigated materials.

The amplitude sweeps of $\left(\mathrm{G}^{\prime}\right)$ and loss $\left(\mathrm{G}^{\prime \prime}\right)$ moduli presented in Fig. 10 revealed strong correlation between consistency and composition (in particular on the content of polar fraction in the 

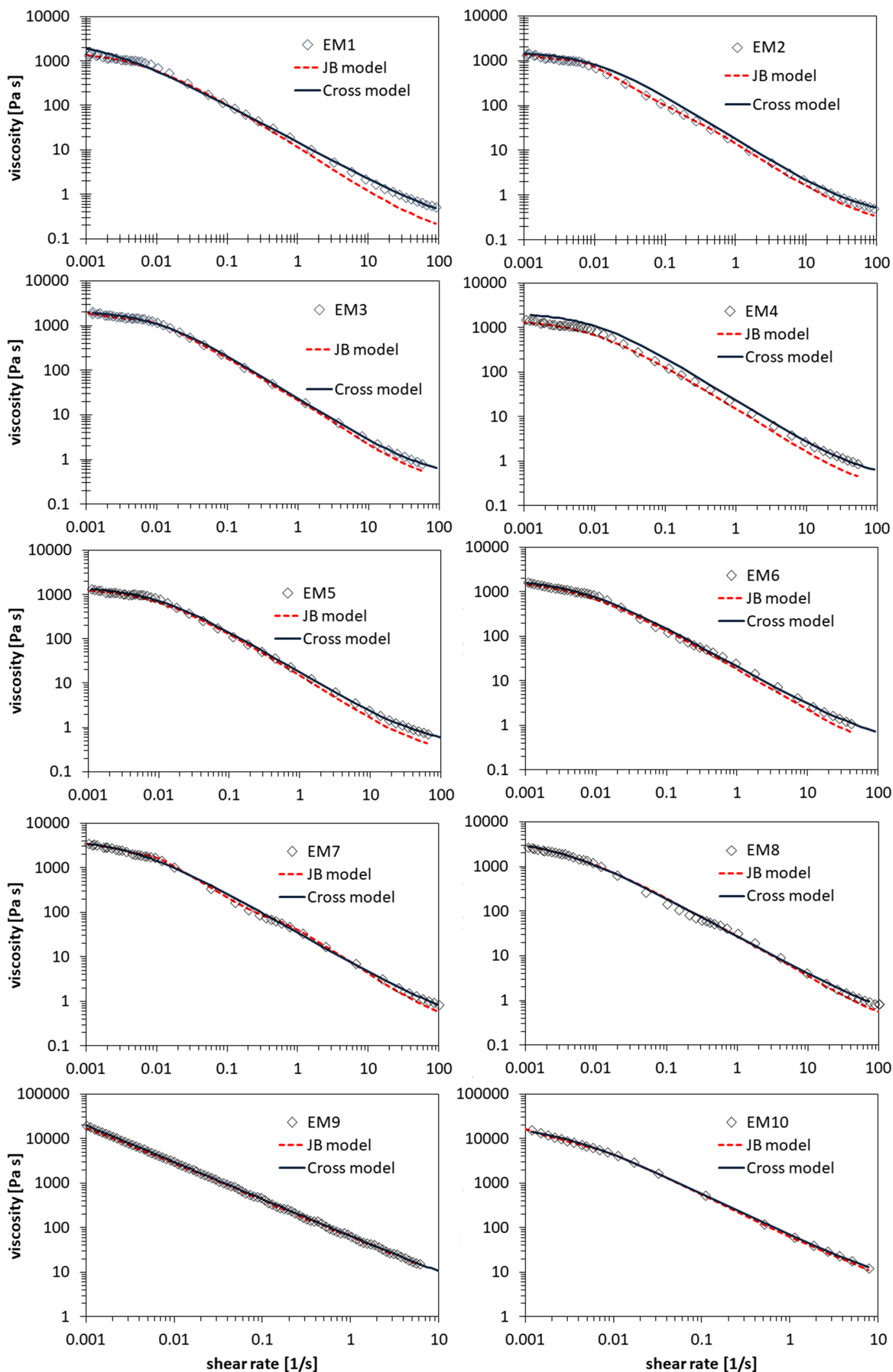

Fig. 9 Viscosity curves of the studied emulsions fitted with Cross and JB models. Measurements performed at $20{ }^{\circ} \mathrm{C}$ on fresh emulsions 

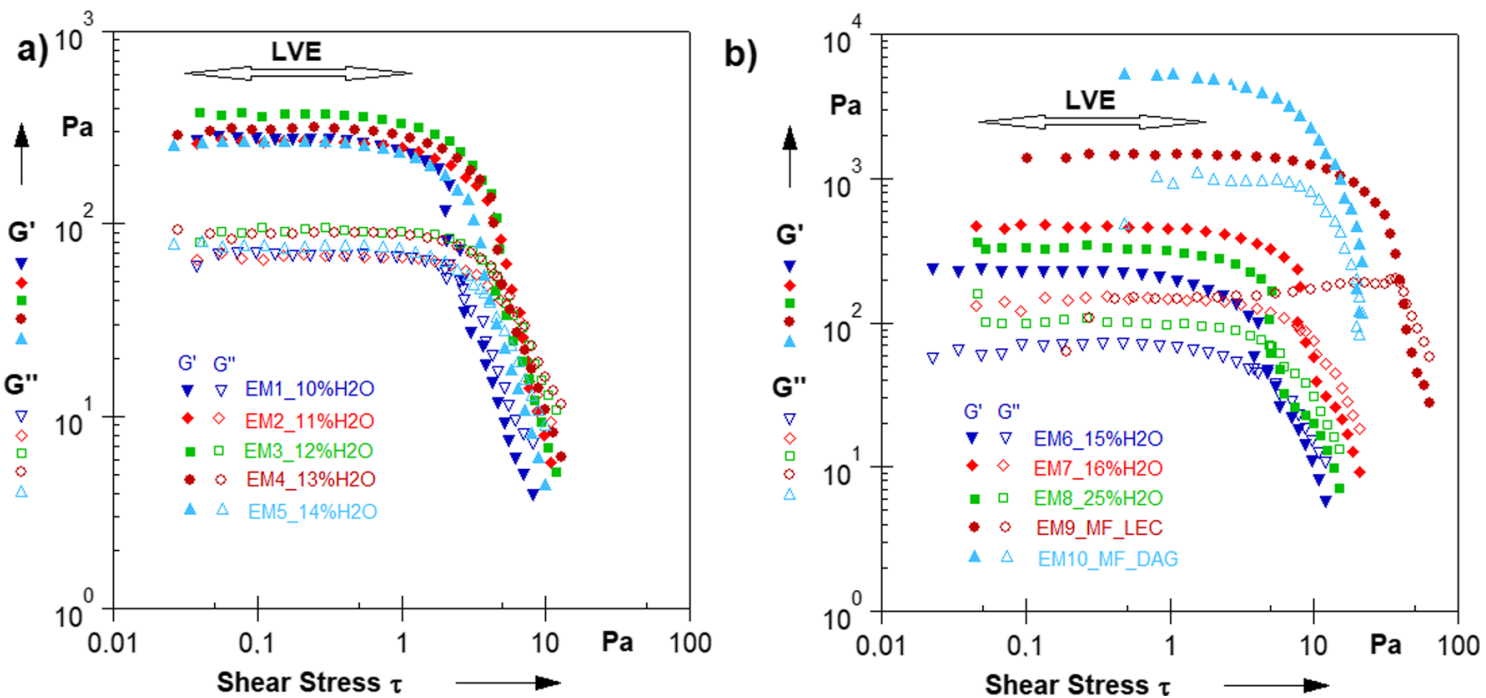

Fig. 10 The change of storage $\left(\mathrm{G}^{\prime}\right)$ and loss $\left(\mathrm{G}^{\prime \prime}\right)$ moduli on the applied oscillatory stress at constant angular frequency $(1 \mathrm{rad} / \mathrm{s})$ for the investigated emulsions
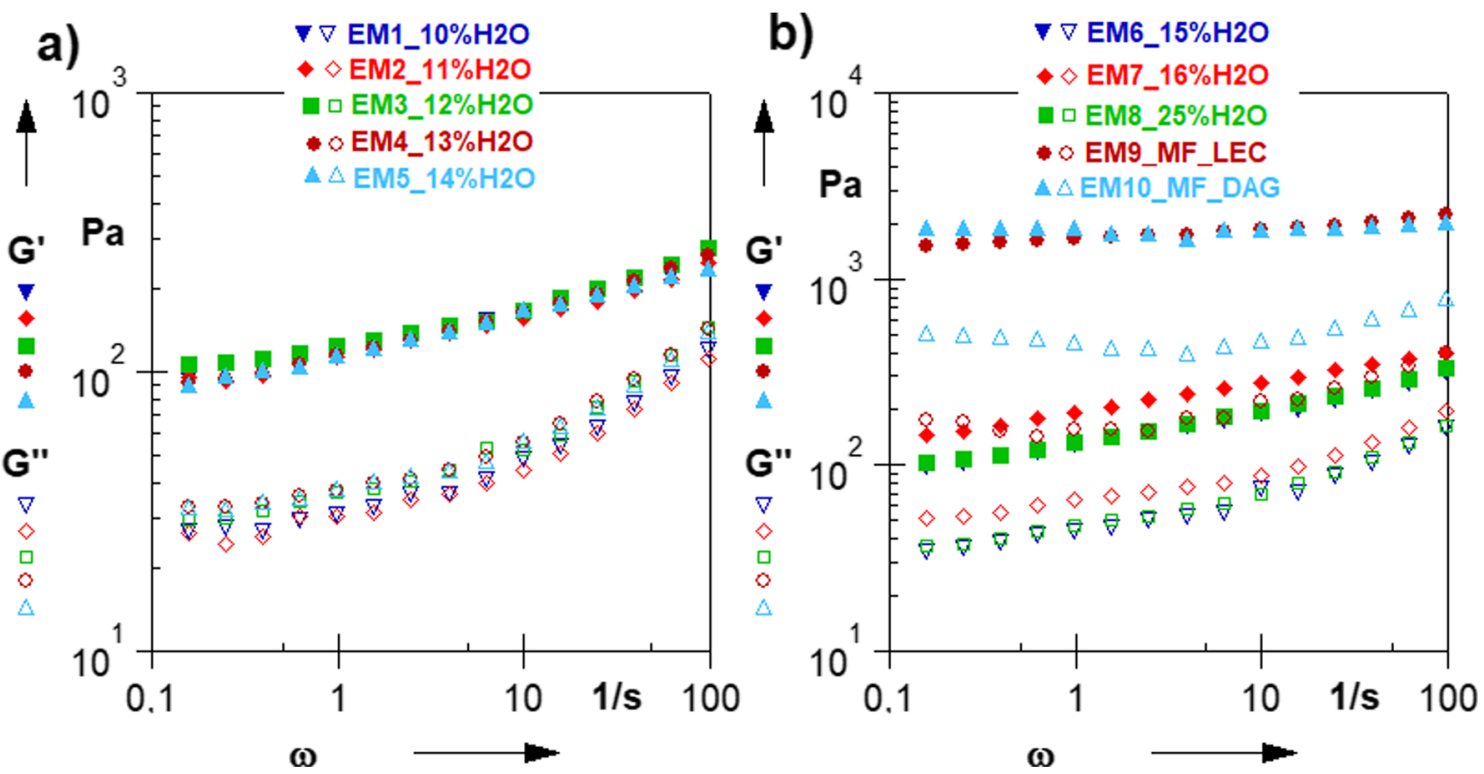

Fig. 11 Frequency sweeps of investigated systems at constant strain amplitude $0.1 \%$ taken from LVE range

Table 4 Results of three-interval tests for investigated systems

\begin{tabular}{|c|c|c|c|c|}
\hline Sample & $\begin{array}{l}\text { Microstructure recovery } \\
\text { after } 1 \mathrm{~s}[\%]\end{array}$ & $\begin{array}{l}\text { Microstructure recovery } \\
\text { after } 60 \mathrm{~s}[\%]\end{array}$ & $\begin{array}{l}\text { Reference apparent } \\
\text { viscosity at } 0.25 \mathrm{~s}^{-1}[\mathrm{~Pa} \mathrm{~s}]\end{array}$ & $\begin{array}{l}\text { Apparent viscosity } \\
\text { at } 500 \mathrm{~s}^{-1}[\mathrm{~Pa} \mathrm{~s}]\end{array}$ \\
\hline EM1_10\% $\mathrm{H}_{2} \mathrm{O}$ & 8.6 & 99.0 & 32.89 & 0.236 \\
\hline $\mathrm{EM} 2 \_11 \% \mathrm{H}_{2} \mathrm{O}$ & 6.5 & 86.6 & 47.81 & 0.268 \\
\hline $\mathrm{EM} 3 \_12 \% \mathrm{H}_{2} \mathrm{O}$ & 7.2 & 92.3 & 56.91 & 0.311 \\
\hline EM4_13\% $\mathrm{H}_{2} \mathrm{O}$ & 9.5 & 100 & 48.82 & 0.349 \\
\hline EM5_14\% $\mathrm{H}_{2} \mathrm{O}$ & 8.8 & 89.1 & 42.94 & 0.317 \\
\hline EM6_15\% $\mathrm{H}_{2} \mathrm{O}$ & 9.6 & 92.7 & 48.63 & 0.362 \\
\hline EM7_16\% $\mathrm{H}_{2} \mathrm{O}$ & 11.5 & 97.0 & 79.39 & 0.392 \\
\hline EM8_25\% $\mathrm{H}_{2} \mathrm{O}$ & 10.1 & 95.0 & 62.68 & 0.384 \\
\hline EM9_MF_LEC & 14.1 & 98.4 & 189.05 & 0.544 \\
\hline EM10_MF_DAG & 56.9 & 107.6 & 148.32 & 0.486 \\
\hline
\end{tabular}




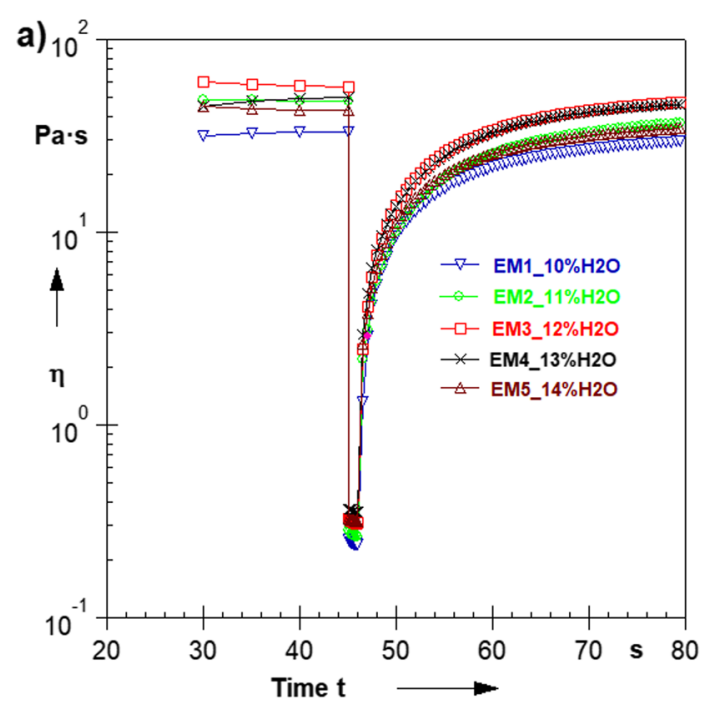

Fig. 12 Microstructure recovery after high shear load for studied systems

fat blends) of the investigated materials. Emulsions containing larger content of polar fractions (EM6, EM7, EM8) exhibit more extended linear viscoelastic range (LVE) and a bit higher values of $\mathrm{G}^{\prime}$ modulus in comparison to emulsions EM1-EM5. Moreover, for emulsions EM7 and E8, $\mathrm{G}^{\prime}$ modulus is approximately two times higher in comparison to the other emulsions containing interesterified fats, although for both of them, these values are far from those obtained for the reference emulsion EM9 stabilized by lecithin. On the other hand, $G^{\prime}$ modulus of emulsion EM10 prepared with synthetic DAG as a stabilizer is very high, although the LVE range is pretty narrow, which suggests moderate stability of this system caused, i.e., by creaming.

Dense emulsions are considered as a deformation-dependent systems characterized by visible dependence of dynamic moduli on the applied frequency and smaller differences between corresponding $\mathrm{G}^{\prime}$ and $\mathrm{G}^{\prime \prime}$ values. To study these relations, we

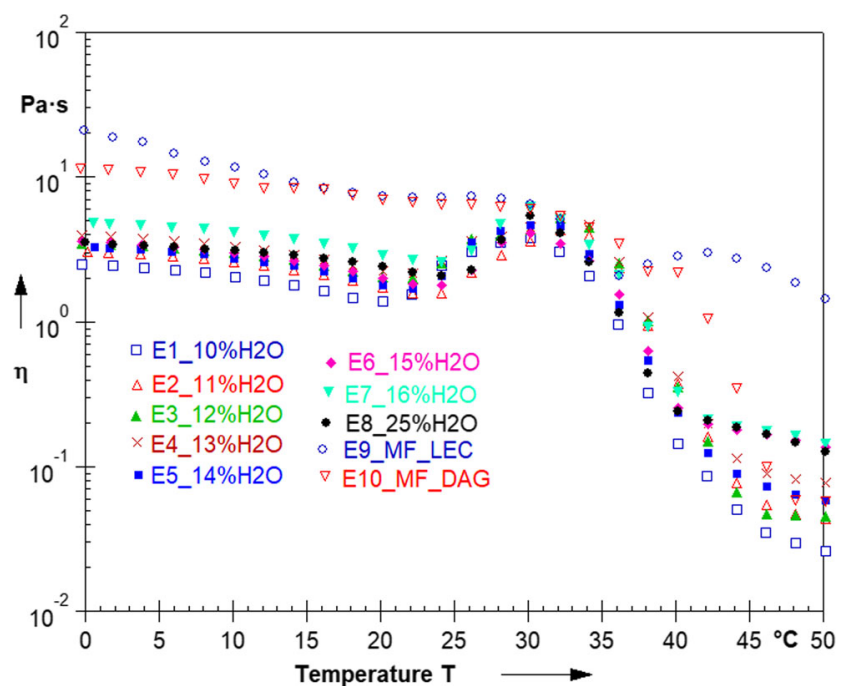

Fig. 13 Temperature scans for investigated emulsions measured at constant shear rate $10 \mathrm{~s}^{-1}$. Heating rate $3{ }^{\circ} \mathrm{C} / \mathrm{min}$

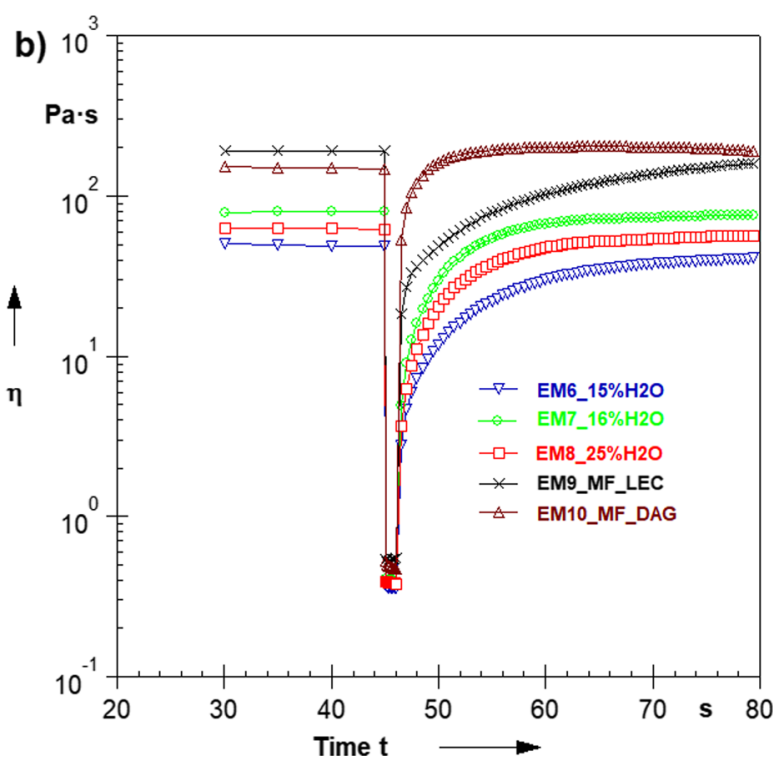

have performed the corresponding frequency tests and their results are shown in Fig. 11. The frequency sweeps show clearly that emulsions containing interesterified fats (EM1-EM8) are more frequency dependent than EM9 and EM10, although the observed changes are rather moderate, as illustrated by relatively small slope of $\mathrm{G}^{\prime}$ at low-frequency regime. This can be considered as evidence of enhanced stability of the investigated materials in the prolonged time period. However, closer look to the low-frequency regimes, one can see that the $\mathrm{G}^{\prime}$ modulus of systems with lower amounts of polar fractions (EM1-EM5) appears to be more frequency dependent, than for emulsions EM6-EM8 that contained higher amounts of polar fractions in the oil phase. Small strain/stress oscillatory tests performed in wide frequency range enable analysis of materials in a time domain. From analysis of $\mathrm{G}^{\prime}$ dependency on frequency at various regimes, one can estimate the time-driven changes of the investigated system, provided that the whole investigation is performed at proper conditions, namely in isothermal conditions under constant strain or stress taken from LVE range.

To estimate the time-dependent structure reformation after shearing, we have performed a three-interval test combining observation of viscosity change before and after applying the high shear rates. The measurements were conducted in three steps. In every step, constant shear rate was applied and the viscosity change in time was recorded. First, the material was equilibrated in the measuring cell over $10 \mathrm{~min}$; then, the reference viscosity was measured at shear rate equal to $0.25 \mathrm{~s}^{-1}$ by collecting few points within $15 \mathrm{~s}$. Next, high shear rate $\left(500 \mathrm{~s}^{-1}\right)$ was applied for $1 \mathrm{~s}$ to disturb the emulsion microstructure; after high shearing period, the shear rate $0.25 \mathrm{~s}^{-1}$ was restored and viscosity was measured within longer period of time. As a result, the information about the percentage of microstructure recovery related to the reference viscosity value is obtained, which enables estimation of emulsion microstructure reconstruction after 
shearing and can be used for testing the relative changes in consistency. The estimated percentages of microstructure recovery after $1 \mathrm{~s}$ and after $60 \mathrm{~s}$ are shown in Table 4.

For emulsion EM10 prepared with synthetic DAG, the viscosity overshoot was observed revealing the microstructure reconstruction higher than $100 \%$ (Fig. 12). This phenomenon is quite often observed in materials capable for formation of stable microstructures resulting from strong interactions between droplets and dispersing media. In such systems, the application of high stresses results in partial microstructure destruction and in the sample volume besides individual droplets larger aggregates appear that may block the flow of the material causing temporary thickening of the measured fluid, which is visible as higher viscosity. With the progress of time of the measurement at constant low shear rate, these aggregates reform and finally the system reaches equilibrium with the viscosity value close to the reference one.

Typical cosmetic emulsions are usually prepared, stored, transported, and utilized at temperatures between 0 and $50{ }^{\circ} \mathrm{C}$; therefore, to study the thermal breakdown of our systems, we have investigated our materials in a rotational mode in this temperature regime. The results are depicted in Fig. 13.

Emulsions containing interesterified fat blends show similar trends in their thermal behavior with visible signs of emulsion destabilization, evidenced by slight increase in viscosity around this temperature followed by its drastic drop above $33{ }^{\circ} \mathrm{C}$. Materials prepared with lecithin and synthetic DAG show similar behavior, although the initial increase in viscosity is less pronounced.

\section{Conclusions}

Our results confirmed that using selective lipase in interesterification process to obtain fats containing appropriate amount of MAG and DAG is a new approach enabling formation of

emulsifiers, which can sufficiently stabilize the new emulsion systems. Physicochemical analysis and rheological evaluation of the presented emulsion systems clearly showed that emulsions containing interesterified fat with addition of 1.00 and $1.25 \%, w / w$, of water during the enzymatic modification constituted the most stable dispersion systems. Turbiscan test results revealed small changes of obtained BS light intensity profiles for these emulsions during the entire storage period.

Rheological analysis revealed that it is possible to prepare stable emulsion systems by application of modified fat mixtures serving as a source of emulsifiers. It has been shown that the content of polar fraction in the interesterified fat blend plays a crucial role in the stability of the emulsion system. Moreover, emulsions based on fats with higher amount of MAG and DAG (EM6-EM8) exhibited wider LVE range and faster microstructure recovery in comparison to EM1EM5 that contained less mono-and diacylglycerols.

The use of a biocatalyst and waste animal fat as well as the minimization of additional substances added to the dispersion systems (formation of emulsifiers already during enzymatic modification of fats) contribute to clean technologies and broadly defined principles of sustainable development. The emulsions obtained due to the presence of only natural components can be used in food and cosmetics industry.

Funding information The work was financially supported by Kazimierz Pulaski University of Technology and Humanities in Radom (Radom, Poland) and the Faculty of Chemistry of Warsaw University of Technology (Warsaw, Poland).

\section{Compliance with ethical standards}

Conflict of interest The authors declare that they have no conflict of interest.

\section{Appendix}

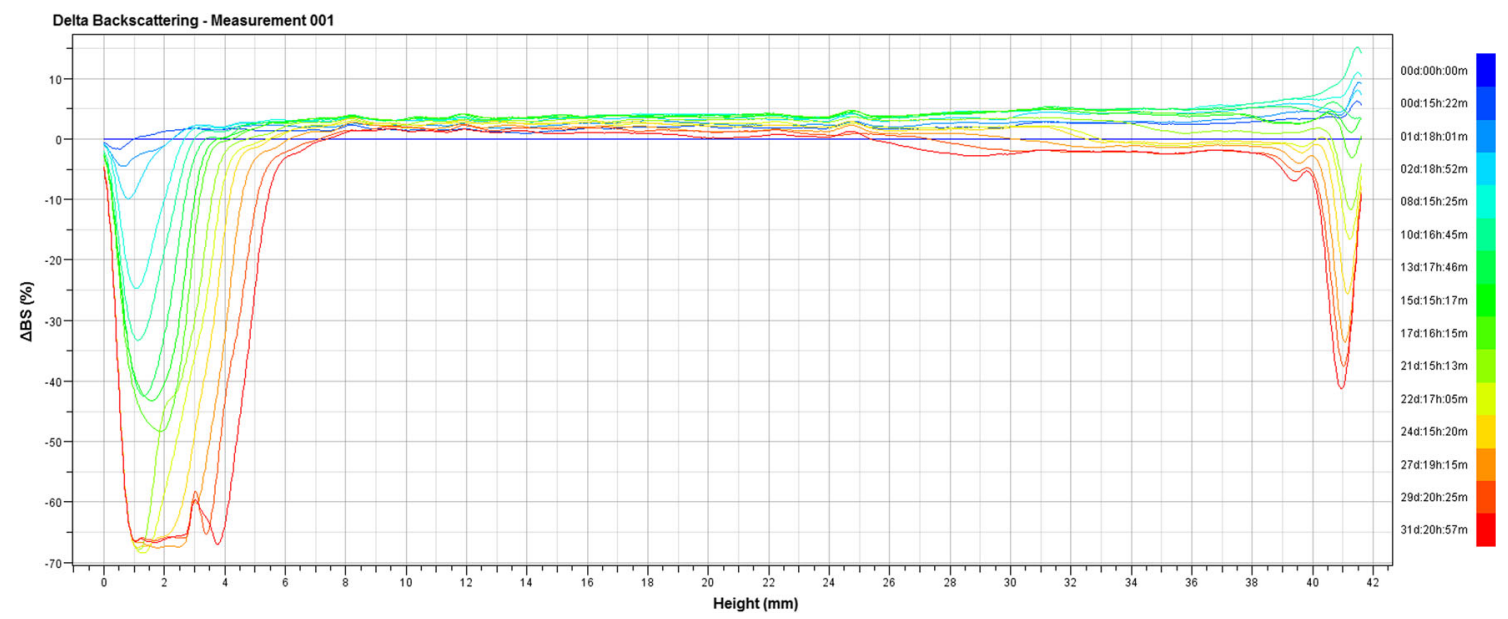

Fig. $14 \Delta \mathrm{BS}$ profile for EM1 as a function of time and sample height 


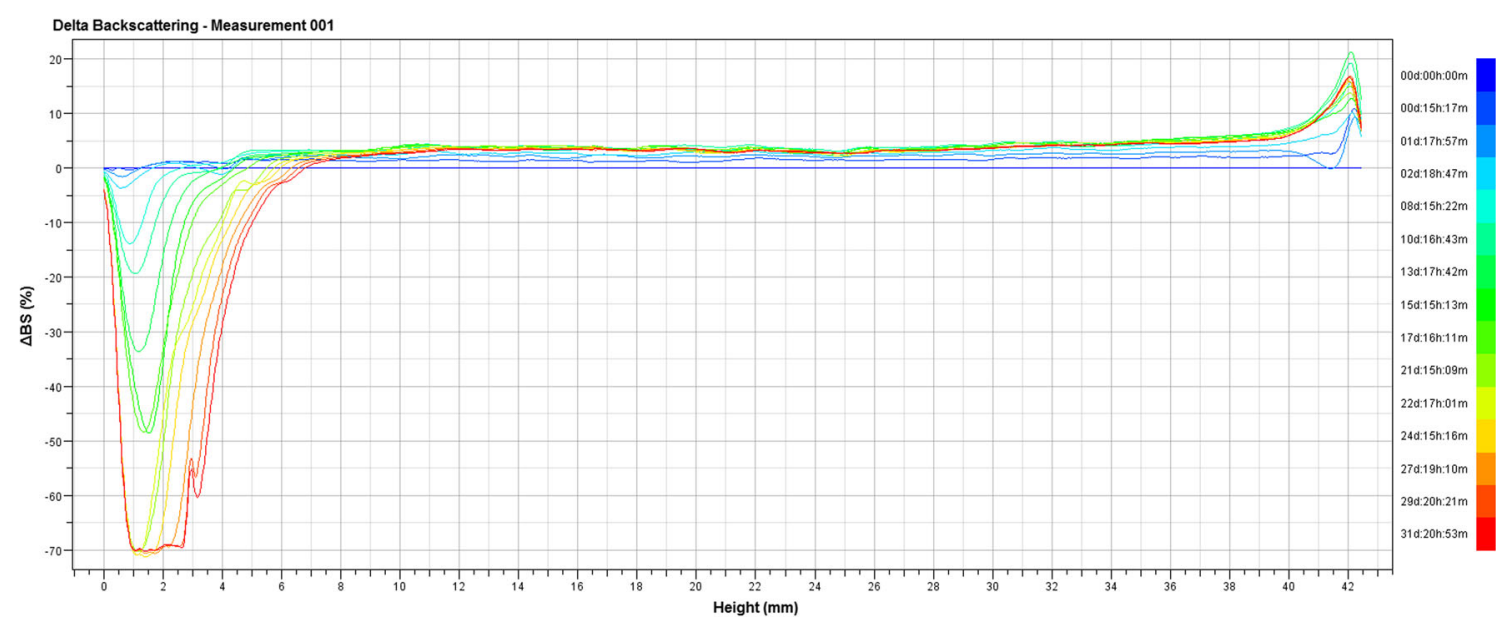

Fig. $15 \triangle \mathrm{BS}$ profile for EM3 as a function of time and sample height

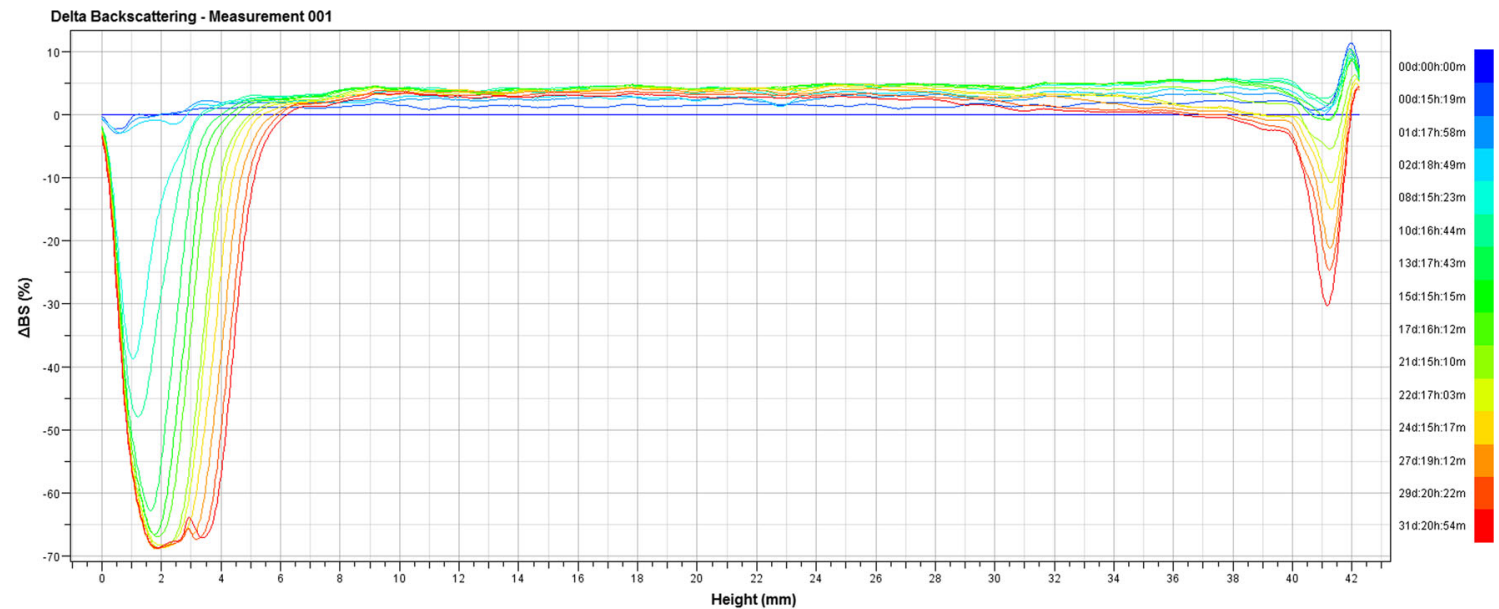

Fig. $16 \Delta \mathrm{BS}$ profile for EM4 as a function of time and sample height

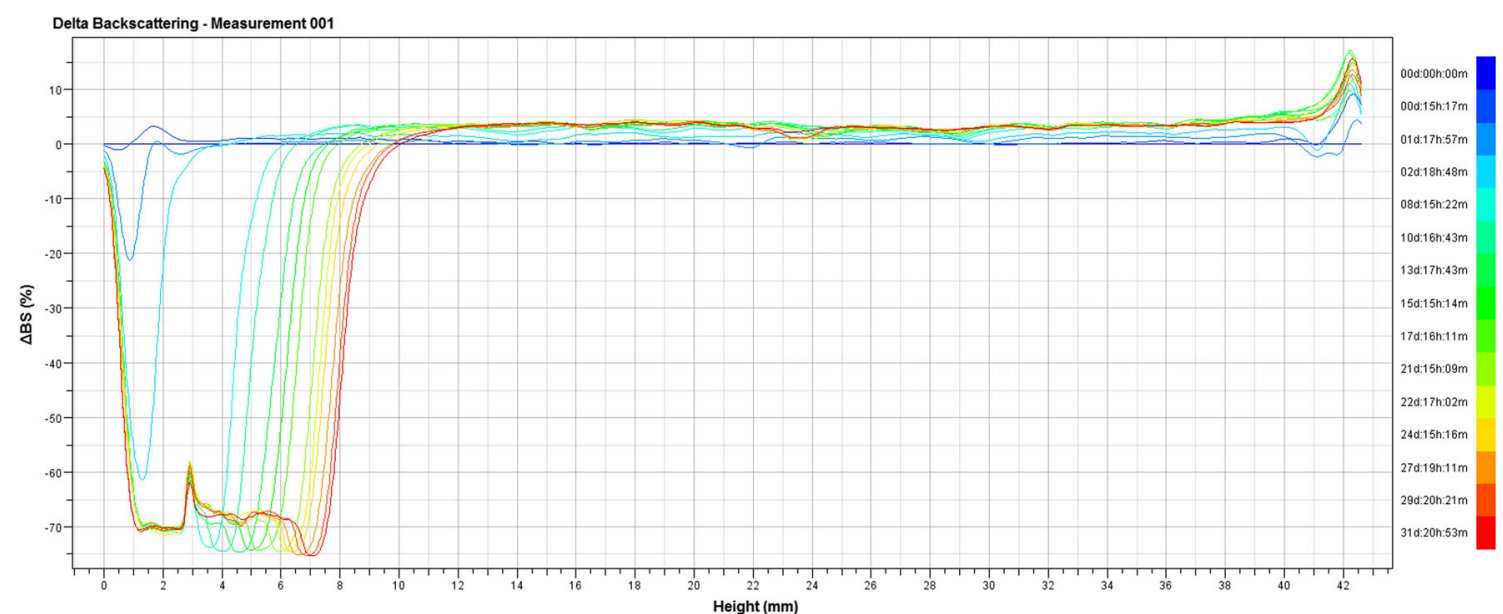

Fig. $17 \Delta \mathrm{BS}$ profile for EM5 as a function of time and sample height 


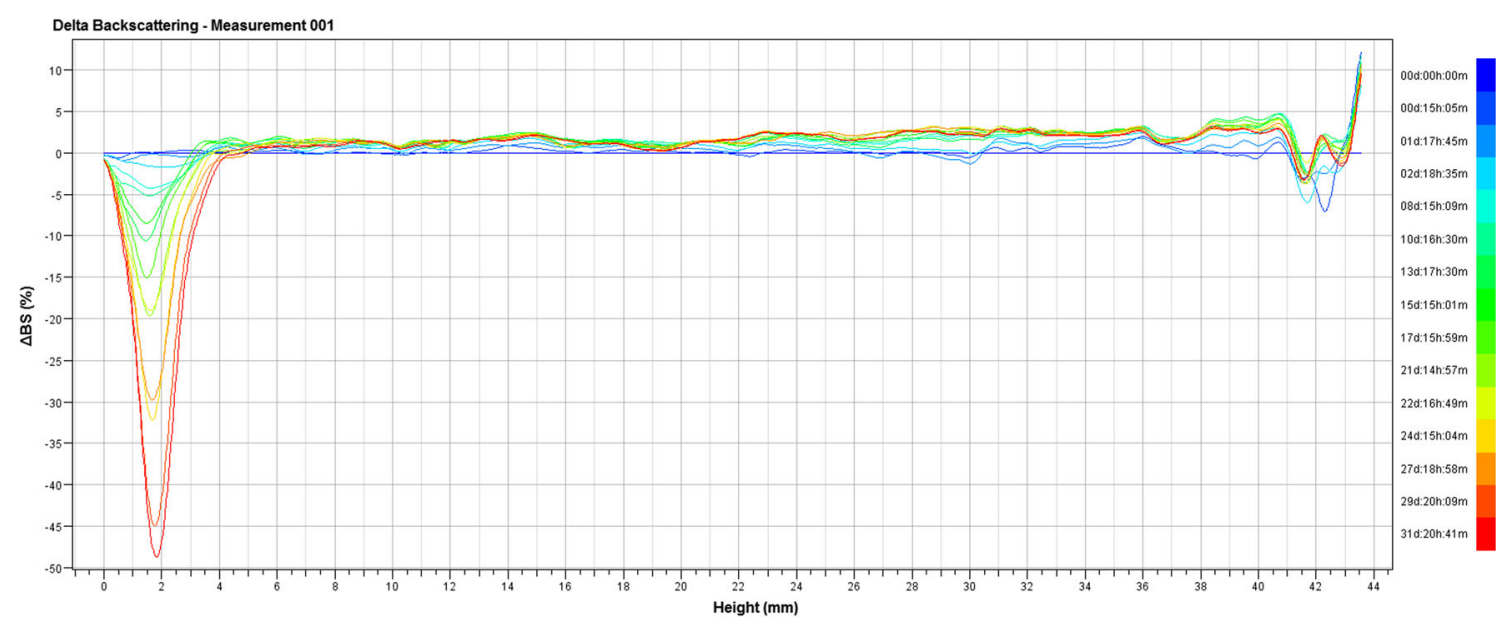

Fig. $18 \Delta \mathrm{BS}$ profile for EM6 as a function of time and sample height

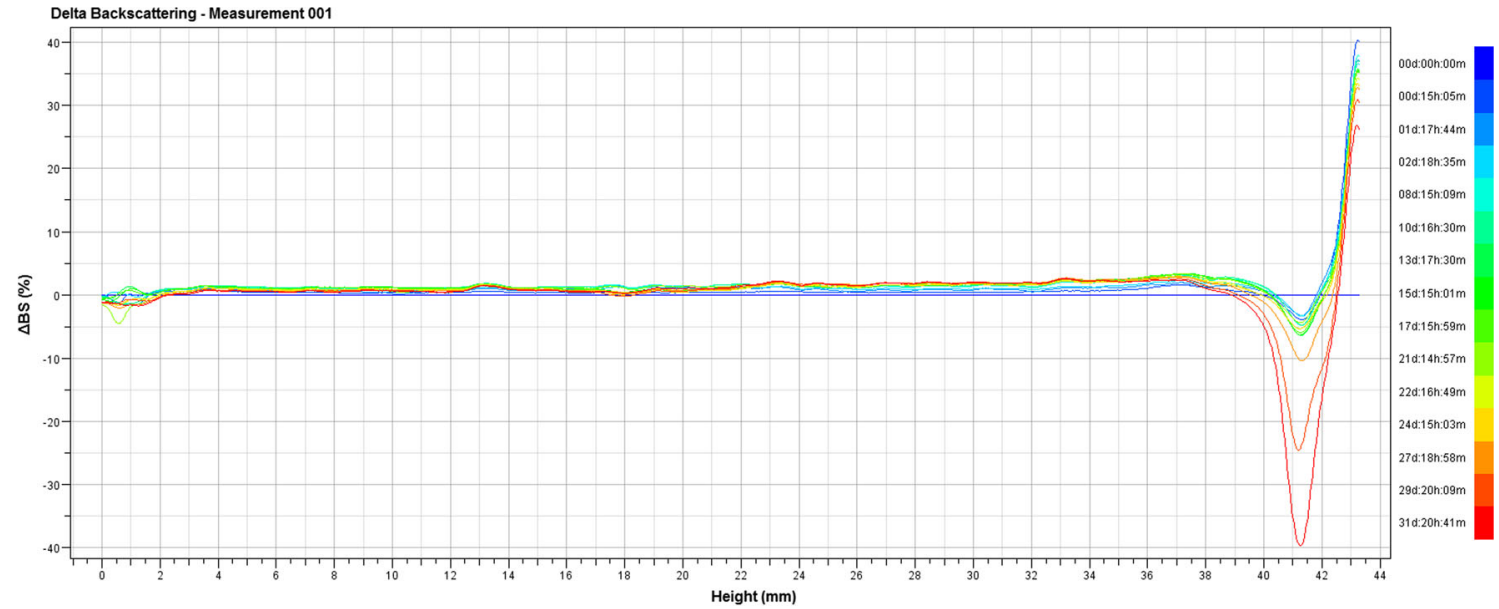

Fig. $19 \Delta \mathrm{BS}$ profile for EM7 as a function of time and sample height

Open Access This article is distributed under the terms of the Creative Commons Attribution 4.0 International License (http:// creativecommons.org/licenses/by/4.0/), which permits unrestricted use, distribution, and reproduction in any medium, provided you give appropriate credit to the original author(s) and the source, provide a link to the Creative Commons license, and indicate if changes were made.

\section{References}

Baldyga J, Jasinska M, Kowalski A (2016) Effect of rheology of dense emulsions on the flow structure in agitated systems. Chem Eng Res Des 108:3-12

Barnes HA (1994) Rheology of emulsions - a review. Colloids Surf A Physicochem Eng Asp 91:89-95
Berry SE (2009) Triacylglycerol structure and interesterification of palmitic and stearic acid-rich fats: an overview and implications for cardiovascular disease. Nutr Res Rev 22(1):3-17

Boelsma E, Hendriks HF, Roza L (2001) Nutritional skin care: health effects of micronutrients and fatty acids. Am J Clin Nutr 73(5): $853-864$

Brümmer R (2006) Rheology essentials of cosmetic and food emulsions. Springer-Verlag, Heidelberg

Cerimedo MSÁ, Iriart CH, Candal RJ, Herrera ML (2010) Stability of emulsions formulated with high concentrations of sodium caseinate and trehalose. Food Res Int 43(5):1482-1493

Chauvierre C, Labarre D, Couvreur P, Vauthier C (2004) A new approach for the characterization of insoluble amphiphilic copolymers based on their emulsifying properties. Colloid Polym Sci 282(10):10971104

Estanqueiro M, Conceição J, Amara MH, Santos D, Silva JB, Lobo JMS (2014) Characterization and stability studies of emulsion systems containing pumice. Braz J Pharm Sci 50(2):361-369 
Gallegos C, Franco JM, Partal P (2004) Rheology of food dispersion. Rheol Rev 2004:19-65

Ghanbari M, Esmaeilzadeh F, Binazadeh M (2017) An experimental investigation of creaming phenomenon using a novel optical method: a case study of mineral oil in water emulsion. J Dispers Sci Technol 39(5):634-643

Gouveia L, Raymundo A, Batista AP, Sousa I, Empis J (2006) Chlorella vulgaris and Haematococcus pluvialis biomass as colouring and antioxidant in food emulsions. Eur Food Res Technol 222(3-4): 362-367

Huck-Iriart C, Candal RJ, Herrera ML (2011) Effect of processing conditions and composition on sodium caseinate emulsions stability. Proc Food Sci 1:116-122

Kowalska D, Gruczyńska E, Kowalska M (2015) The effect of enzymatic interesterification on the physico-chemical properties and thermooxidative stabilities of beef tallow stearin and rapeseed oil blends. J Therm Anal Calorim 120(1):507-517

Lortie R (1997) Enzyme catalyzed esterification. Biotechnol Adv 15(1): $1-15$

Macosko CW, Larson RG (1994) Rheology: principles, measurements and applications. Wiley-VCH, Inc, Weinheim

McClements DJ (2005) Food emulsions. Principles, practices and techniques, 2nd edn. CRC Press, Boca Raton

McClements DJ (2007) Critical review of techniques and methodologies for characterization of emulsion stability. Crit Rev Food Sci Nutr 47(7):611-649

Mengual O, Meunier G, Cayre I, Puech K, Snabre P (1999) Characterisation of instability of concentrated dispersions by a new optical analyser: the TURBISCAN MA 1000. Colloids Surf A Physicochem Eng Asp 152(1-2):111-123

Paiva AL, Balcao VM, Malcata FX (2000) Kinetics and mechanisms of reactions catalyzed by immobilized lipases. Enzym Microb Technol 27(3):187-204

Pal R (1996) Effect of droplet size on the rheology of emulsions. AICHE J 42(11):3181-3190

Pal R (2001) Novel viscosity equations for emulsions of two immiscible liquids. J Rheol 45(2):509-520

Pal R (2003) Viscous behavior of concentrated emulsions of two immiscible Newtonian fluids with interfacial tension. J Colloid Interface Sci 263:296-305
Palazolo GG, Sorgentini DA, Wagner JR (2005) Coalescence and flocculation in $\mathrm{o} / \mathrm{w}$ emulsions of native and denatured whey soy proteins in comparison with soy protein isolates. Food Hydrocoll 19(3):595604

Palierne JF (1990) Linear rheology of viscoelastic emulsions with interfacial tension. Rheol Acta 29:204-214

Pazdur Ł, Geuens J, Sels H, Tavernier SM (2015) Low-temperature chemical synthesis of high-purity diacylglycerols (DAG) from Monoacylglycerols (MAG). Lipids 50(2):219-226

Ribeiro APB, Basso RC, Grimaldi R, Gioielli LA, Gonçalves LA (2009) Instrumental methods for the evaluation of interesterified fats. Food Anal Methods 2(4):282-302

Robins MM (2000) Emulsions-creaming phenomena. Curr Opin Colloid Interface Sci 5(5-6):265-272

Rustan AC, Drevon CA (2005) Fatty acids: structures and properties. eLS. Wiley-VCH, Inc., Weinheim

Salager J-L, Briceno MI, Bracho CL (2001) Heavy hydrocarbonemulsions. Making use of the state of the art in formulation engineering. In: Sjoblom J (ed) Encyclopedic handbook of emulsion technology. Marcel Dekker, New York, Chapter 20, pp 455-495

Schowalter WR, Chaffey CE, Brenner H (1968) Rheological behavior of a dilute emulsion. J Colloid Interface Sci 26(2):152-160

Sharma R, Chisti Y, Banerjee UC (2001) Production, purification, characterization, and applications of lipases. Biotechnol Adv 19(8):627662

Tarnowska K, Kostecka M, Piotrkowicz A, Łobacz M, Kowalski B (2013) Interesterification of goose fat and rapeseed oil mixture using Candida rugosa lipase immobilized in alginate beads. Riv Ital Sostanze Gr 40:95-105

Teh SS, Birch J (2013) Physicochemical and quality characteristics of cold-pressed hemp, flax and canola seed oils. J Food Compos Anal 30(1):26-31

Wiktorowska-Owczarek A, Berezinska M, Nowak JZ (2015) PUFAs: structures, metabolism and functions. Adv Clin Exp Med 24(6): 931-941

Publisher's note Springer Nature remains neutral with regard to jurisdictional claims in published maps and institutional affiliations. 